\title{
Effect of phytoplankton growth on air bubble residence time in seawater
}

\author{
V. Kuhnhenn-Dauben, ${ }^{1}$ D. A. Purdie, ${ }^{2}$ U. Knispel, ${ }^{3}$ H. Voss, ${ }^{3}$ and U. Horstmann ${ }^{1}$ \\ Received 20 March 2007; revised 16 December 2007; accepted 15 February 2008; published 10 June 2008.
}

[1] Laboratory experiments were carried out in a seawater mesocosm tank to investigate the influence of marine phytoplankton growth on air bubble residence time (BRT). Air bubbles of $10-1000 \mu \mathrm{m}$ in diameter were injected by flushing a water jet into the top of the tank and BRT was determined acoustically. The tank was filled with seawater containing a natural phytoplankton population and growth stimulated by irradiating with artificial fluorescent light. A second experiment was conducted using a monoculture of the diatom Cylindrotheca closterium. BRT and several phytoplankton growth-related parameters (chlorophyll concentration, dissolved inorganic nutrients, dissolved organic carbon (DOC), oxygen saturation and bacteria numbers) as well as the water viscosity were monitored over periods of up to 24 days. BRT showed a statistically significant covariation with oxygen saturation $(\mathrm{r}=0.69, \alpha=0.01$ for natural phytoplankton; $\mathrm{r}=0.93$, $\alpha=0.01$ for the Cylindrotheca closterium) and chlorophyll concentration ( $\mathrm{r}=0.69, \alpha=$ 0.05 natural phytoplankton; $\mathrm{r}=0.76, \alpha=0.01$ Cylindrotheca closterium) during phytoplankton growth periods. Increases in BRT of a factor $>2$ were found during the chlorophyll maximum, when the water was sufficiently supersaturated with oxygen $(\sim>110 \%)$. No clear relationship was evident between BRT and measurements of DOC or water viscosity. Model experiments with highly oxygen-supersaturated water and artificial polysaccharide compounds indicated that oxygen supersaturation alone is not the main factor causing increased BRT during phytoplankton growth, but it is most likely a combination of the degree of gas saturation and the composition of the organic exudates derived from the microalgal population.

Citation: Kuhnhenn-Dauben, V., D. A. Purdie, U. Knispel, H. Voss, and U. Horstmann (2008), Effect of phytoplankton growth on air bubble residence time in seawater, J. Geophys. Res., 113, C06009, doi:10.1029/2007JC004232.

\section{Introduction}

[2] Air bubbles in the upper layer of the ocean play an important role in several physical processes of biogeochemical significance [Thorpe, 1982; Woolf, 1997] and act as a vehicle for the transport of material to the surface microlayer [Scott, 1975; Gershey, 1983; Wallace and Duce, 1978]. The primary mechanism by which organic particles are transported upward across the boundary between the ocean and the atmosphere is associated with the production of aerosol particles which in turn is the result of bubbles bursting at the sea surface [Blanchard and Woodcock, 1957; Blanchard, 1963; Deane and Stokes, 2002; Monahan and Dam, 2001]. Air bubbles are also involved in the exchange of gases between the atmosphere and the ocean [Merlivat and Memery, 1983; Asher et al., 1996; Woolf, 1995; Nightingale and Liss, 2004]. Wallace and Wirick [1992]

\footnotetext{
${ }^{1}$ Leibniz-Institut für Meereswissenschaften, Kiel, Germany.

${ }^{2}$ University of Southampton, National Oceanography Centre, European Way, Southampton, UK.

${ }^{3}$ Forschungsanstalt der Bundeswehr für Wasserschall und Geophysik, Kiel, Germany.

Copyright 2008 by the American Geophysical Union. 0148-0227/08/2007JC004232\$09.00
}

found that increased wave action results in increased oxygen concentrations in the sea via bubble entrainment and they reviewed the importance of air bubbles in the cycling and global budget of trace gases. Air bubbles, especially those produced in the wakes of ships by propeller cavitation, are also of great interest to those involved in naval operations as they may interfere with the successful function of acoustic devices by scattering and absorbing sound due to their large acoustic cross section [Trevorrow et al., 1994].

[3] It is known that air bubbles remain in the water column for different periods of time [Graham et al., 2004]. Reasons for the differences in residence time of air bubbles have been found mainly to be due to the physical and chemical properties of seawater such as water temperature [Thorpe, 1986; Thorpe and Hall, 1987; Hwang et al., 1991], salinity [Scott, 1975; Peltzer and Griffin, 1988; Craig et al., 1993; Wang and Monahan, 1995] and the level of gas saturation [Ramsey, 1962; Harris and Detsch, 1991; Woolf and Thorpe, 1991; Keeling, 1993; Bowyer and Woolf, 2004].

[4] It is assumed, that biological factors in the ocean, especially phytoplankton, also have a major effect on the residence time of air bubbles through their influence on the gas saturation of seawater [Sandler et al., 1982; Zakharkov 


\section{Solenoid valve}

Blocking valve

$\square$ Pump

Float switch

Fill level sensor

Stroke magnet

Flow meter

Oxygen electrode

i LF Transmitter ITC 1042

1. Receiving Hydrophone TC 4014

I HF Transmitter TC 4034

1 Temp/Conductivity Sensor

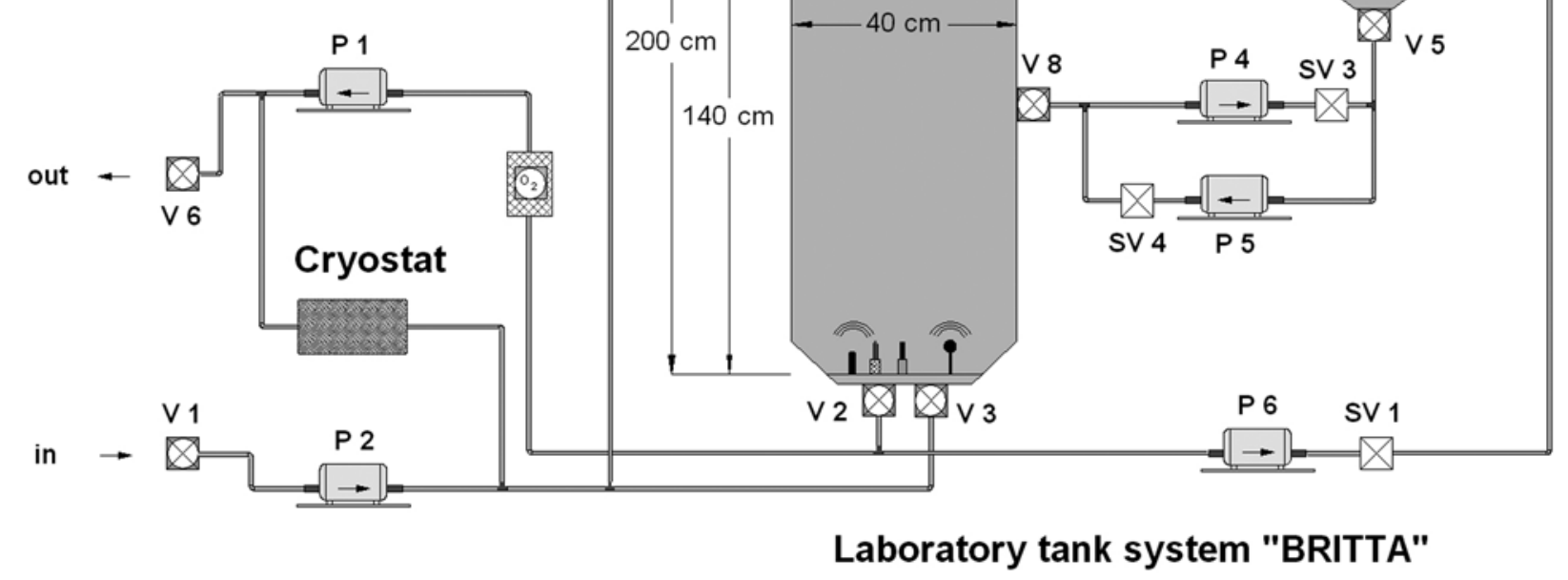

Figure 1. Schematic diagram of laboratory experimental tank system.

et al., 1991] and through the release of organic substances such as polysaccharides [Leppard, 1995; Mopper et al., 1995; Myklestad, 1995]. These organic substances may result in changes in bubble surface tension [Nägeli and Schanz, 1991; Slauenwhite and Johnson, 1996] and the viscosity of seawater [Petkov and Bratkova, 1996] and may thus alter the rise speed of bubbles [Detwiler, 1979; Thorpe et al., 1992; Patro et al., 2001] as well as the diffusion of gas to and from the bubble [Thorpe et al., 1992].

[5] In regions of high biological production, spring-, summer- and early autumn phytoplankton blooms may influence bubble characteristics in near surface waters such as the residence time and the number of bubbles formed. Visual evidence for the extended residence times of air bubbles in the wakes of ships can sometimes be seen in Kiel Firth for example, when surface foam lines are visible for long periods after a ship has passed during low wind speed and calm weather conditions. However, not much is known about the relationship between the residence time of bubbles in seawater and biological activity.
[6] The aim of this work was to investigate if phytoplankton abundance, growth and their metabolic products of dissolved oxygen and dissolved organic material (DOM) can influence the mean residence time of gas bubbles in seawater. The main objectives were (1) to determine if bubble residence time (BRT) changes during different growth phases of phytoplankton populations, using a monoculture of the diatom Cylindrotheca closterium and mixed species in natural seawater, (2) to investigate the effect of phytoplankton abundance on seawater viscosity and compare this with bubble residence time, and (3) to determine the causes of changes in BRT in relation to phytoplankton particle abundance, oxygen production and phytoplankton exudates, that may act as surfactants in seawater.

\section{Methodology}

\subsection{Laboratory Tank System}

[7] Experiments were carried out in a specially designed laboratory experimental tank system (Figure 1) fitted with an acoustic detection system. The large bubble tank consisted of a $200 \mathrm{~cm}$ long, transparent plexi-glass tube, $40 \mathrm{~cm}$ 


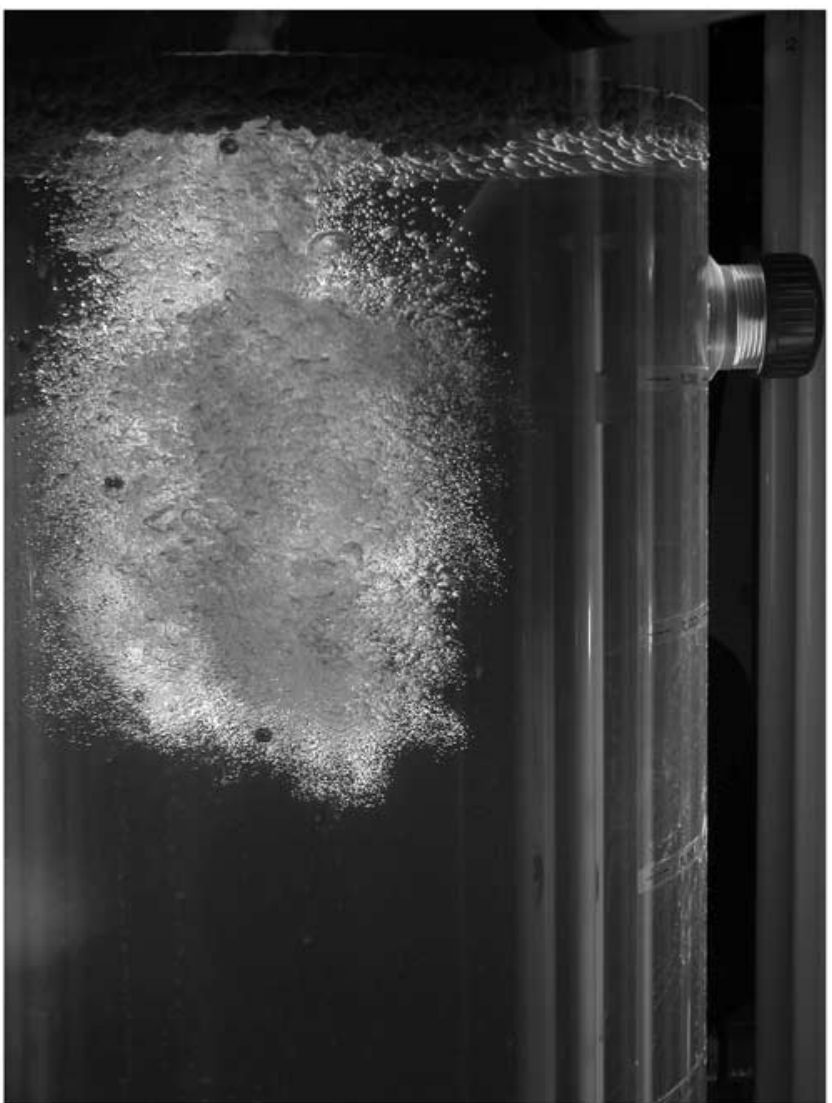

Figure 2. Injection of bubble cloud into the tank system by a water splash.

in diameter. The top of the tank was covered by a lid containing two holes, $8 \mathrm{~cm}$ in diameter, for air exchange with the atmosphere. The water surface was covered with small plastic balls $(6 \mathrm{~mm}$ in diameter), that served to optimize the acoustic signal reflection from the surface. A small supply tank was mounted on top of the plexi-glass tube. From this supply tank, a water volume of 0.81 was injected into the bubble tank, producing the bubble cloud (Figure 2). The size range of bubbles produced was between $10-1000 \mu \mathrm{m}$ in radius. The size of the largest bubbles was determined by photographing the bubble cloud. The size of the smallest bubbles could not be directly determined via the measurement set-up but is assumed to have been not $<10 \mu \mathrm{m}$ in radius according to Vagle and Farmer [1992]. A balancing tank at the side of the tank system acted as a water level equilibrator. All tanks were interlinked via Teflon tubing, covered with opaque foam insulation. The water circulation system included a cryostat (Aquamedic) to maintain a constant water temperature in the bubble tank and the supply tank. A total of 6 membrane pumps and 5 solenoid valves enabled the circulation of water between the different tanks as well as through the cryostat (Figure 1). Pumps and valves were operated via a relay matrix by the control software developed using Matlab. A tungsten fill level sensor in the large tank adjusted the water level. A temperature/conductivity probe (WTW Cond 340i) as well as an oxygen sensor (WTW Profi Line Oxi 197) were integrated into the tank system to monitor temperature, salinity and dissolved oxygen. A flowmeter controlled the water volume that was injected into the bubble tank by the water jet. The bubble cloud was monitored using two transmitting hydrophones (ITC 1042 band $=0.01-100 \mathrm{kHz}$, resonance frequency $=79 \mathrm{kHz}$ and TC $4034 \mathrm{band}=1 \mathrm{~Hz}-$ $470 \mathrm{kHz}$, resonance frequency $=300 \mathrm{kHz}$ ) and one receiving hydrophone (TC 4034 band $=15 \mathrm{~Hz}-480 \mathrm{kHz}$ ) attached to the base of the bubble tank. The tank system was illuminated by 12 special plant fluorescent tubes (Osram L58 W/77), which were fitted on two opposite sides of the bubble tank to stimulate phytoplankton growth. The experimental tank system was operated automatically via the control software.

\subsection{Measurement Cycle}

[8] The measurement cycle was the time interval between successive measurements of BRT. Measurements of BRT were always carried out at constant water temperature. The duration of a measurement cycle varied between 1 and $1.5 \mathrm{~h}$, depending on the pre-selected water temperature. Measurements of BRT were carried out with frequencies ranging from 40 to $400 \mathrm{kHz}$, subdivided into two frequency bands $(40-180 \mathrm{kHz}$ and $180-400 \mathrm{kHz})$. For a measurement cycle, only one frequency band could be sampled. A measurement cycle began with the adjustment of the water level in the large tank to a height of $140 \mathrm{~cm}$ and the filling of the supply tank, followed by the turbulence-and-cooling phase, when the water in the bubble tank was pumped through the cryostat, until the predefined measurement temperature was reached. Once the set measurement temperature was achieved, a 20 min quiescent phase commenced after which the acoustic sampling began. Following a $30 \mathrm{~s}$ initial period of acoustic sampling, the bubble cloud was produced by the water jet (duration $2 \mathrm{~s}, 0.8 \mathrm{l}$ ). The acoustic sampling then continued for another $19.5 \mathrm{~min}$.

\subsection{Determination of Bubble Residence Time}

[9] Initially, the reference backscatter level was defined, comprising the first $30 \mathrm{~s}$ of the acoustic measurement phase before the release of the water jet. A mean reference value was calculated for all acoustic pings for every frequency. A standardization was then carried out for the remaining pings (from the time the water jet was released until the end of the acoustic measurement phase) with the corresponding reference value. The backscatter level was plotted over time and depth (Figure 3). A value of BRT for a certain frequency was then determined by applying a detection threshold. The detection threshold was set in the near surface layer to a level of $3 \mathrm{~dB}$. BRT was then defined as the time when the backscatter level near the water surface fell below the detection threshold.

[10] In this paper, BRT values are presented for a frequency of $120 \mathrm{kHz}$ only as previous observations of in situ bubble clouds by FWG (unpublished data) have shown strongest damping at this particular frequency.

\subsection{Sampling}

[11] Collection of water samples for measurements of chemical, biological and physico-chemical parameters was carried out once a day. Samples were drawn from a tap fitted mid way up the bubble tank. Triplicate $120 \mathrm{ml}$ volumetric glass bottles were filled for the determination 


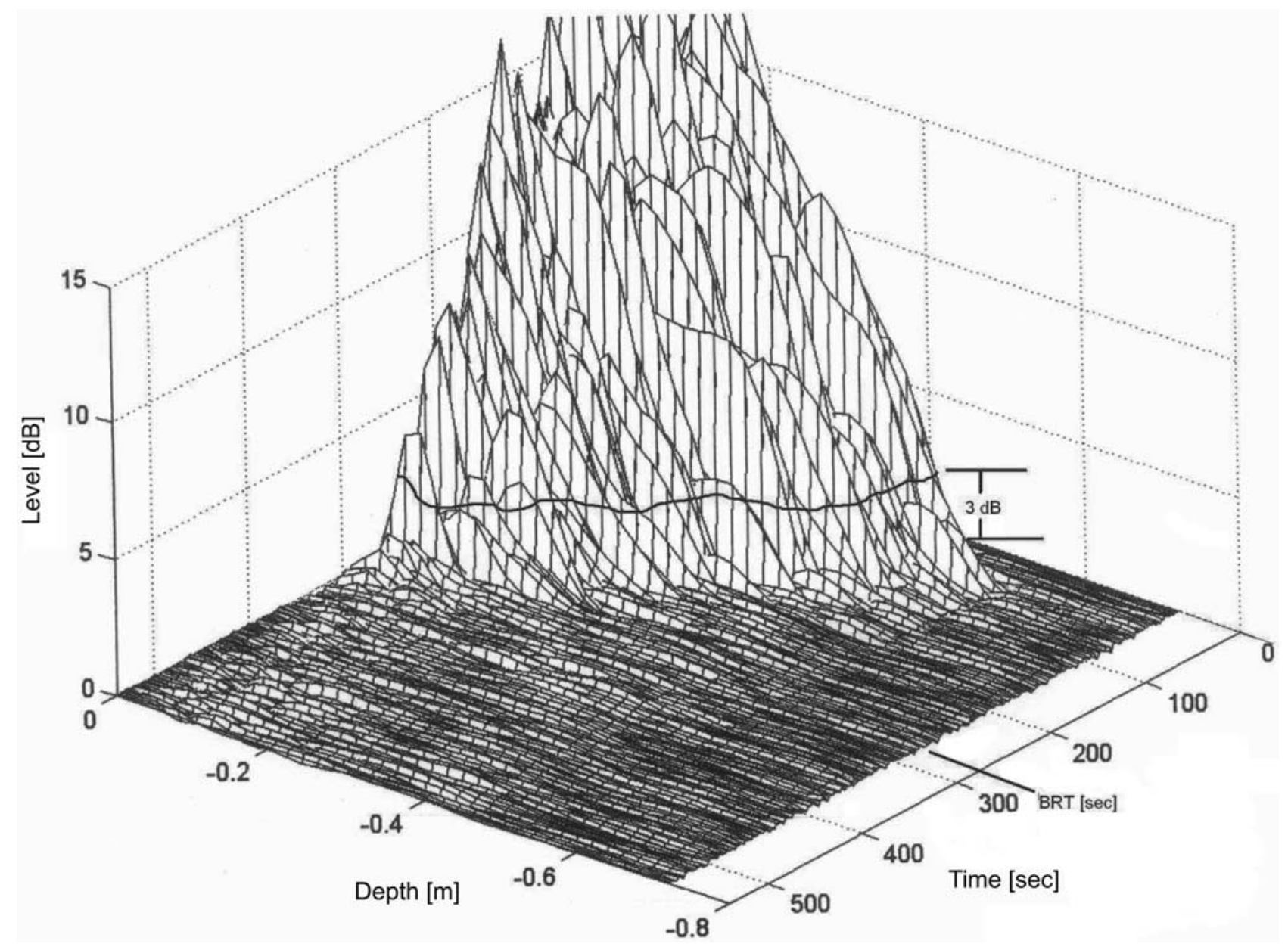

Figure 3. Backscatter level of the acoustic signal at $120 \mathrm{kHz}$ over time and for different water depths of the tank system. The black line along the backscatter signal indicates the $3 \mathrm{~dB}$ threshold. The BRT is indicated on the time-axis at $280 \mathrm{~s}$.

of dissolved oxygen and $1 \mathrm{ml}$ of each Winkler reagent (manganese (II) chloride and alkaline iodide solution) added. Samples were analyzed using the Winkler procedure as described by Grasshoff et al. [1999] and a Hydro Bios titration system. A sample for filtration and further analysis of dissolved organic carbon (DOC) was poured directly from the tap into a $500 \mathrm{ml}$ Schott glass flask, which had been prerinsed with the sampling water and was closed with a Teflonlined lid. A large volume of about 1.51 of tank water was poured into a plastic measuring jug for later sub-sampling for dissolved inorganic nutrients, chlorophyll $a$, phytoplankton cell counts, bacteria cell counts, and viscosity measurements.

[12] Samples for analysis of chlorophyll $a$ were filtered in triplicate through Whatman glass fiber filters $(\mathrm{GF} / \mathrm{F})$ with a vacuum of between $0.2-0.3$ bar. Filters were frozen at $-40^{\circ} \mathrm{C}$, then extracted in $90 \%$ acetone overnight and analyzed using a Turner GAT TD 10AU fluorometer as described by Welschmeyer [1994]. Samples for the analysis of dissolved inorganic nitrate, nitrite, phosphate and silicate were filtered in triplicate through Whatman GF/F filters and frozen in $100 \mathrm{ml}$ plastic bottles at $-40^{\circ} \mathrm{C}$. Dissolved inorganic nutrients were analyzed according to the method described by Grasshoff et al. [1999]. Samples for the analysis of DOC were filtered through pre-combusted $\left(500^{\circ} \mathrm{C}\right.$ for $\left.12 \mathrm{~h}\right) \mathrm{GF} / \mathrm{F}$ filters with a pressure filtration system at 0.5 bars. The filtrate was decanted into $40 \mathrm{ml}$ precombusted glass vials in triplicate, spiked with $150 \mu \mathrm{l} 50 \%$ $\mathrm{H}_{3} \mathrm{PO}_{4}$ and closed with Teflon-lined caps. Determination of dissolved organic carbon was done by high temperature catalytic oxidation [Sharp, 1973], using a Shimadzu TOC 5000A organic carbon analyzer (for the natural Kiel Firth phytoplankton experiment) and a Shimadzu TOC-V $\mathrm{CSN}_{\mathrm{C}}$ organic carbon analyzer (for the experiment with Cylindrotheca closterium).

[13] $50 \mathrm{ml}$ samples for bacteria counts were decanted into clean brown glass bottles and fixed with $1 \mathrm{ml}$ of $37 \%$ prefiltered formaldehyde. Samples were then filtered through black polycarbonate filters, stained with acridine orange [Hobbie et al., 1977] and counted using a Zeiss Axioplan epifluorescence microscope with HBO 50 mercury vapor light and a blue-filter (450-490 nm).

[14] Samples for phytoplankton cell counts were placed into $250 \mathrm{ml}$ clean brown glass bottles and fixed with $5 \mathrm{ml}$ of Lugol's iodine solution (Merck). Phytoplankton cells were counted following the method described by Utermöhl [1958] with a Zeiss inverted microscope.

[15] A $3 \mathrm{ml}$ sample was decanted into an Ostwald capillary glass viscometer (capillary diameter $=0.4 \mathrm{~mm}$ ) 
for the determination of bulk water viscosity. The principle of this method is based on the time taken for a fluid to pass a given distance through a small capillary, from which the kinematic viscosity (which is an indication of the internal friction of a fluid) is calculated using:

$$
v=K \bullet t
$$

where $v$ is the kinematic viscosity, $K$ the capillary constant ( 0.01 for a capillary with diameter $=0.4 \mathrm{~mm})$ and $t$ is the time (in seconds) it takes for the fluid to pass a certain distance through the capillary. Viscosity measurements were made in a temperature controlled water bath (Lauda) at the same water temperature that was selected for the experimental tank system. 10 replicate measurements were made on every sample.

\subsection{Preparation and Implementation of the Kiel Firth Nutrient Enriched Seawater Experiment}

[16] 3001 of Kiel Firth water were pumped into plastic containers (the containers had previously been rinsed with deionized water) in January 2004 at the Kiel lighthouse on board the research vessel "Polarfuchs". A Johnson membrane pump was used to pump the water from approximately five meters below the sea surface. The water was transferred into the tank system on the same day it was sampled and the measurement software was started. The water temperature in the tank was set to $12^{\circ} \mathrm{C}$. The fluorescent tubes were operated on a 12/12 h light/dark cycle (only 6 tubes were used). Initially the water jet was suppressed for a period of two days to let the water degas. Following this, the jet was switched on and bubble residence time measurements began. After four measurement cycles, $50 \mathrm{ml} \mathrm{NaNO}_{3}, 50 \mathrm{ml}$ $\mathrm{Na}_{2} \mathrm{HPO}_{4}$ and $50 \mathrm{ml} \mathrm{Na} \mathrm{SiO}_{3}$ stock solution as well as $50 \mathrm{ml}$ of Vitamin Mix and $5 \mathrm{ml}$ of each metal stock solution of $F / 2$ nutrient medium were added to the water to stimulate algal growth and BRT measurements were made for 13.5 consecutive days. Daily samples for the analysis of biological, chemical and physico-chemical parameters were taken from day 0.5 .

\subsection{Preparation of the Cylindrotheca Closterium Culture}

[17] A non-axenic stock culture of Cylindrotheca closterium was subcultured into five $100 \mathrm{ml}$ sterile glass flasks, filled with F/10 nutrient medium [Guillard and Ryther, 1962], made up from 11 filtered (GF/F), sterile seawater (salinity 31) spiked with $200 \mu \mathrm{l}$ of $\mathrm{NaNO}_{3}, 200 \mu \mathrm{l}$ of $\mathrm{Na}_{2} \mathrm{HPO}_{4}, 200 \mu \mathrm{l}$ of $\mathrm{Na}_{2} \mathrm{SiO}_{2}$ stock solutions as well as $1 \mathrm{ml}$ of vitamin mix stock solution and $100 \mu \mathrm{l}$ of each metal stock solution. The initial ratio of stock culture and F/10 nutrient medium was approximately $1: 10$. All culture flasks were sealed with sterile cellulose stoppers and covered with aluminum foil. Algae were grown in a temperature controlled room at $18^{\circ} \mathrm{C}$ and were illuminated by fluorescent tubes for $12 \mathrm{~h}$ per day. The diatom cultures were left to grow for seven days, until they showed a distinct, slightly brownish color. The cultures were then transferred into five $300 \mathrm{ml}$ sterile glass flasks and filled up with fresh F/10 nutrient medium. After a further seven days, the cultures were transferred into two 61 glass flasks, each containing 51 of fresh F/10 nutrient medium. The cultures were then left to grow until they showed a distinct brownish coloring.

\subsection{Preparation and Implementation of the Monoculture Growth Experiment With Cylindrotheca Closterium}

[18] The aim of this growth experiment was to investigate the influence of Cylindrotheca closterium on BRT in the tank system, as this particular species is well known for its production of mucilagineous material [Revelante and Gilmartin, 1991].

[19] The tank system was filled with filtered (GF/F) aged North Sea water in October 2004 and measurements of BRT were started immediately at $18^{\circ} \mathrm{C}$ with the fluorescent tubes switched off. After one day, $40 \mathrm{ml} \mathrm{NaNO} 3,40 \mathrm{ml} \mathrm{Na} 2 \mathrm{HPO}_{4}$ and $40 \mathrm{ml} \mathrm{Na} \mathrm{SiO}_{3}$ stock solution as well as $135 \mathrm{ml}$ of Vitamin Mix and $20 \mathrm{ml}$ of each metal stock solution of F/2 nutrient medium were added to the tank followed by 10 litres of a dense monoculture of the diatom Cylindrotheca closterium. Daily samples for the analysis of biological, chemical and physico-chemical parameters were taken from day 1.5. After addition of the culture, six fluorescent tubes were operated on a 12/12 h light/dark cycle and measurements of BRT as well as sampling for all other parameters were carried out for a further 22 days. From day 12 to day 14, the light/ dark interval of the fluorescent tubes was changed in error to $24 \mathrm{~h}$ and was set back to $12 \mathrm{~h}$ from midday on day 14 until the end of the experiment.

\subsection{Preparation and Implementation of the Oxygen Supersaturation Experiment}

[20] BRT measurements were made using deionized water, which had been in the tank system for several days at a temperature of $18^{\circ} \mathrm{C}$. After 1.5 days, the deionized water was bubbled with pure oxygen from a pressurized bottle via a wooden frit, increasing the oxygen saturation of the tank water from $96.8 \%$ to $170 \%$. BRT measurements were then carried out for a further 1.2 days.

\subsection{Preparation and Implementation of the Experiment With Xanthan Gum}

[21] The tank system was filled with deionized water and BRT measurements were started at a temperature of $18^{\circ} \mathrm{C}$. After four days, a solution of the polysaccharide Xanthan Gum (Sigma) was added to the water, resulting in a Xanthan Gum concentration of approximately $0.008 \mathrm{~g} \mathrm{l}^{-1}$. After one day, the oxygen saturation of the tank water was increased to $143 \%$ by bubbling with oxygen from a pressurised bottle. After a further measurement cycle, the concentration of Xanthan Gum was increased to approximately $0.08 \mathrm{~g}^{-1}$. Kinematic viscosity of the tank water was measured several times throughout the experiment. After the second addition of Xanthan Gum, measurements of BRT were carried out for a further 6 days.

\section{Results}

\subsection{Nutrient Enriched Kiel Firth Water}

[22] A growth experiment with water from Kiel Firth, containing a natural plankton population dominated by diatoms was of particular interest as diatoms are known to 

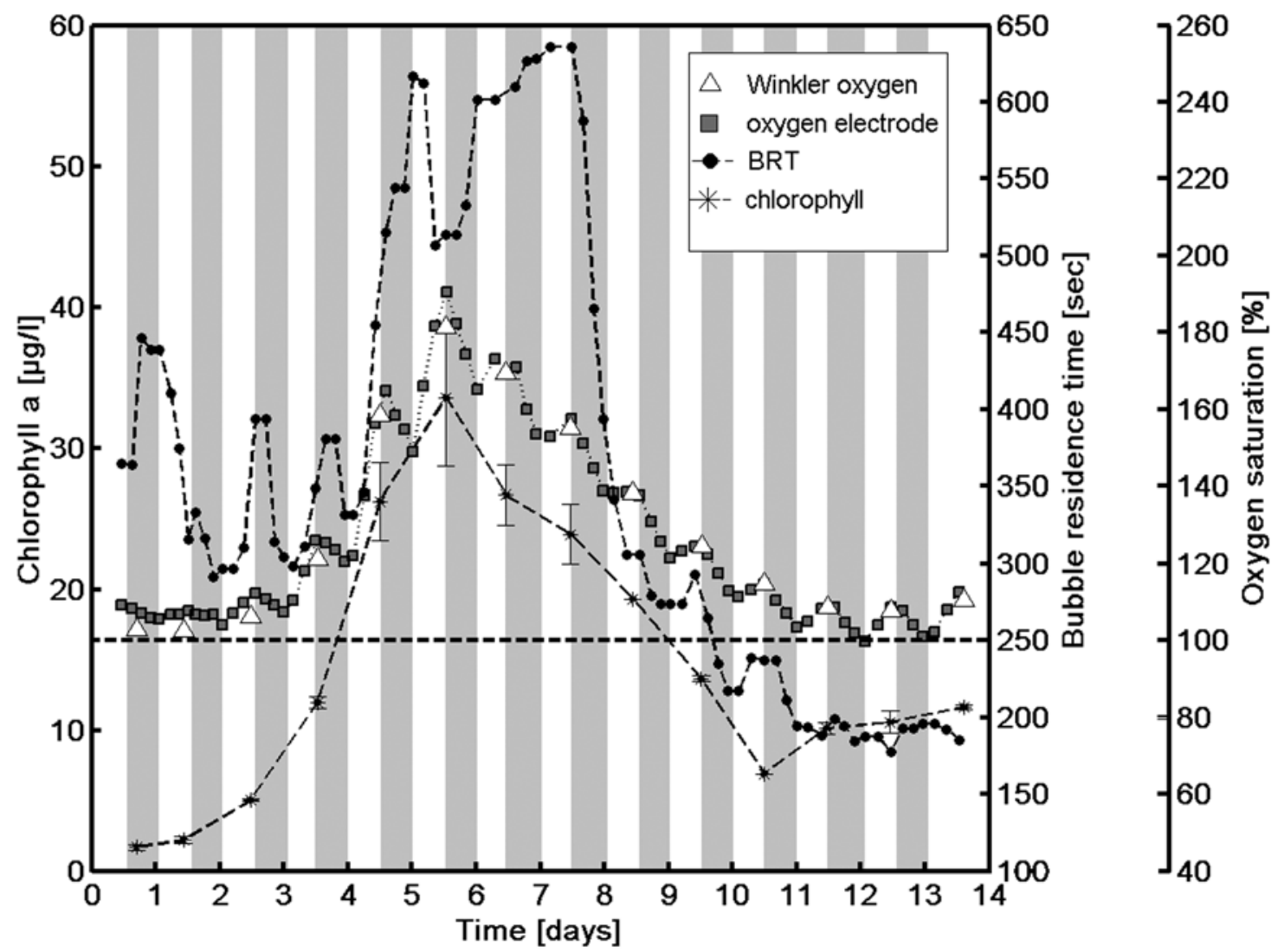

Figure 4. Changes in chlorophyll $a$ concentration, BRT and oxygen saturation (\%) with time for a growth experiment with nutrient enriched Kiel Firth water. The grey shaded bars indicate periods when the tank illumination was switched off, the white bars indicate the times when the tank system was illuminated. The black dashed line indicates the $100 \%$ oxygen saturation threshold.

release large quantities of surface active organic compounds [Mopper et al., 1995] and therefore likely to influence BRT in the tank system.

[23] Water was collected from Kiel Firth on the day the experiment was started and an addition of nutrient medium made on day 0.7 , with initial nutrient concentrations being $219 \mu \mathrm{mol} 1^{-1} \mathrm{NO}_{3}^{-}, 12 \mu \mathrm{mol} \mathrm{l^{-1 }} \mathrm{PO}_{4}^{3-}$ and $50 \mu \mathrm{mol} \mathrm{l}^{-1}$ $\mathrm{SiO}_{4}$. The removal ratio of $\mathrm{NO}_{3}^{-}: \mathrm{PO}_{4}^{3-}$ was usually less than the Redfield ratio of 16 ( 2 between days $2.5-3.5$ and 7.4 between days 3.5-4.5). The growth limiting nutrient was silicate, which became depleted to $<2 \mu \mathrm{mol} 1^{-1}$ on day 5.5. Chlorophyll $a$ concentration in the tank increased exponentially from $1.7 \mu \mathrm{g} \mathrm{l}^{-1}$ to a maximum of $33.6 \mu \mathrm{g} \mathrm{l}^{-1}$ on day 5.5 (Figure 4) indicating that the tank system supported good phytoplankton growth. After day 5.5, the chlorophyll concentration decreased again to $6.9 \mu \mathrm{g} \mathrm{l}^{-1}$ on day 10.5 followed by another slight increase to $10.5 \mu \mathrm{g} \mathrm{l}^{-1}$ on day 12.5. The standard deviation of mean chlorophyll concentrations calculated from triplicate samples was usually below $10 \%$ with a standard deviation of around $4 \%$ for most values.

[24] The phytoplankton in the tank system were dominated by diatoms, with the most abundant species being Thalassionema nitzschioides, Skeletonema costatum, Thalassiosira sp. and Cylindrotheca closterium. On day 0.5 , the most dominant species was Thalassionema nitzschioides $\left(2.7 \times 10^{5}\right.$ cells $\left.1^{-1}\right)$ followed by Skeletonema costatum $\left(1.0 \times 10^{5}\right.$ cells $\left.1^{-1}\right)$, Thalassiosira $\mathrm{sp} .\left(3.8 \times 10^{4}\right.$ cells $\left.1^{-1}\right)$ and Cylindrotheca closterium $\left(1.7 \times 10^{4}\right.$ cells $\left.1^{-1}\right)$. Skeletonema costatum showed the highest specific growth rate during the exponential phase (1 division per day between days $0.5-4.5$ ), and dominated the mixed diatom population while Thalassionema nitzschioides, Cylindrotheca closterium and Thalassiosira sp. had lower specific growth rates. The increase in chlorophyll concentration was accompanied by a rapid increase in oxygen saturation of the water from an initial supersaturation of $102 \%$ (values from oxygen electrode) to a maximum of $190 \%$ on day 5.5, when the chlorophyll concentration was at maximum (Figure 4). The accuracy of the oxygen data from the electrode (recorded 6-7 times per day) was monitored by daily Winkler titrations and the data showed good agreement. The light and dark changes in oxygen saturation as shown on Figure 4 varied by a difference of $10 \%$ between the dark phase minimum and the light phase maximum at the beginning of the phytoplankton growth period (day 2.0) to a maximum difference of approximately $40 \%$ between days 4.0 and 6.0 , when chlorophyll concentrations were maximum. Once the chlorophyll concentration started to decline from day 6.5 , the oxygen supersaturation decreased and light-dark differences diminished, with the light-phase rate of in- 


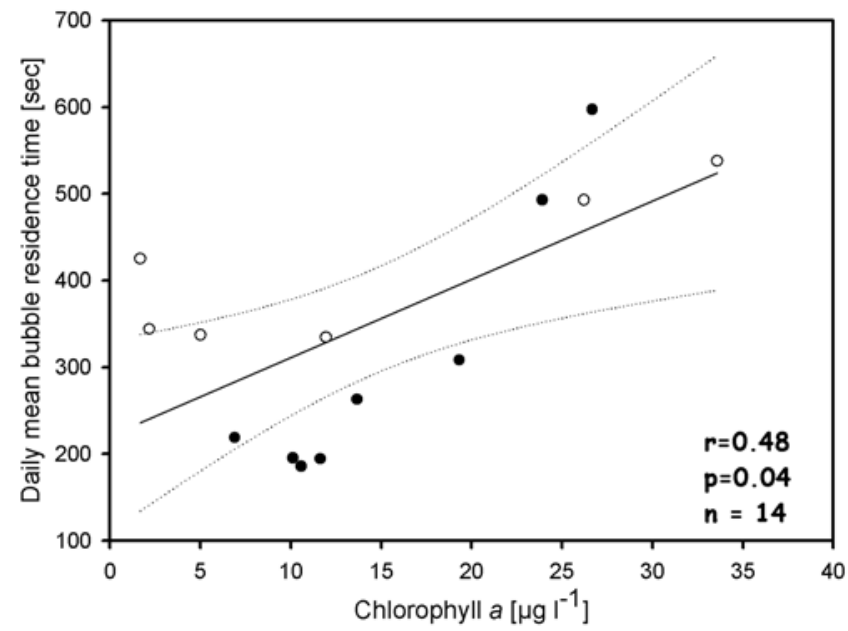

Figure 5. Chlorophyll $a$ concentration versus mean daily BRT for Kiel Firth water growth experiment. Black solid line $=$ linear regression; black dotted lines $=95 \%$ confidence intervals; open symbols $=$ data points during chlorophyll increase; filled symbols $=$ data points during chlorophyll decrease. Averaging intervals were between 5-7 BRT measurement points depending on the number of measurements made per day.

crease in oxygen saturation being less than the rate of decline during dark phase. After 13 days, the oxygen saturation had reduced back to its initial value of just over $100 \%$.

[25] During the first two days of the experiment, when chlorophyll concentrations were still low $\left(\sim 2 \mu \mathrm{g} \mathrm{l}^{-1}\right)$ BRT decreased from $450 \mathrm{~s}$ to just less than $300 \mathrm{~s}$ (Figure 4). This initial decrease in BRT may have been due to organic material from the bulk fluid being scavenged by bubbles. When the bubbles burst on the water surface, the resulting jet droplets may have carried much of this organic material into the head space of the tank, where a fraction was deposited on the tank walls. As the amount of organic material in the bulk water was reduced by this process, subsequent bubbles remained "cleaner" for longer periods of time and thus rose more rapidly for a greater time until they collected enough organic material to make them "dirty" and thus slow their rise down. During days 2.0 to 4.0, BRT increased to $400 \mathrm{~s}$ during the light phase and decreased to $300 \mathrm{~s}$ during dark phase, indicated by the shaded areas in Figure 4. From day 4-5.5, when chlorophyll concentration was $25-33 \mu \mathrm{g}^{-1}$, oxygen supersaturation increased rapidly and the rate of increase during light phase was also high, BRT increased to a maximum value of over $620 \mathrm{~s}$ on day 5.0 , followed by a decline on the same day to $500 \mathrm{~s}$ and a further increase between days 6.0-8.0. Between days 4.5 and 9.0, when the water was highly supersaturated with oxygen, a clear light and dark cycle in BRT was not detectable. From days 9.0-10.5, when chlorophyll concentration and oxygen saturation both declined to $6 \mu \mathrm{g} \mathrm{l}^{-1}$ and $\sim 105 \%$ respectively, BRT decreased to $200 \mathrm{~s}$. Between days 9.0-11.0, when oxygen saturation and BRT declined, BRT showed again some indication of following the light and dark phases indicated by the grey and white shaded areas on Figure 4. Daily chlorophyll concentration and daily mean BRT did not show a particularly strong correlation over the 14 day period of the experiment with a correlation coefficient $\mathrm{r}=0.48$, a $\mathrm{p}$-value of $0.04, \mathrm{n}=14$, (correlation is significant at an $\alpha$-level of 0.05 , Figure 5). BRT showed a general covariation with oxygen saturation and both parameters were highly correlated (Figure 6; $\mathrm{r}=$ $0.69 ; \mathrm{p}$-value $=0.00 ; \mathrm{n}=77 ; \alpha$-level $=0.01$ ). DOC concentration in the tank remained fairly constant during the exponential growth phase (days 2-6) with values around $260-270 \mu \mathrm{mol} \mathrm{l}^{-1}$ (Figure 7). As the chlorophyll concentration reached its maximum on day 5.5 and then began to decrease, the DOC concentration in the tank increased steadily up to $340 \mu \mathrm{mol}^{-1}$ on day 13.5 . DOC concentration did not show any obvious trend with BRT.

[26] Bulk water viscosity did not show a detectable change over time during the experiment (Figure 7). The range of values of viscosity were between $1.197 \mathrm{~mm}^{2} \mathrm{~s}^{-1}$ and $1.201 \mathrm{~mm}^{2} \mathrm{~s}^{-1}$ with an average standard deviation of $0.004 \mathrm{~mm}^{2} \mathrm{~s}^{-1}$. Bacterial abundance did not show any obvious relationship with BRT with cell concentrations around $6 \times 10^{6}$ cells $\mathrm{ml}^{-1}$ except for days $6-9$, when

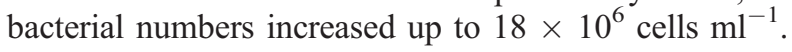

\subsection{Monoculture Growth Experiment With Cylindrotheca Closterium}

[27] The aim of this experiment was to investigate the influence of the growth of the mucilaginous producing diatom Cylindrotheca closterium [Revelante and Gilmartin, 1991] on BRT in the tank system. Nutrients and algae were added to filtered North Sea water on day 1.5 of the experiment, giving initial nutrient concentrations of $320 \mu \mathrm{mol} 1^{-1} \mathrm{NO}_{3}^{-}, 11.5 \mu \mathrm{mol} 1^{-1} \mathrm{PO}_{4}^{3-}$ and $25.0 \mu \mathrm{mol}$ $1^{-1} \mathrm{SiO}_{4}$. The ratio of nitrate to phosphate uptake was close to Redfield from days $1.5-2.5$ (removal ratio $\sim 11$ ) and days $3.5-4.5$ (removal ratio $\sim 15$ ). Between days $2.5-3.5$, nitrate was removed more rapidly than phosphate (nutrient removal ratio of $\sim 6$ ) and later during the experiment (days 4.5-8.5) phosphate was taken up more rapidly (removal ratios $>26$ ).

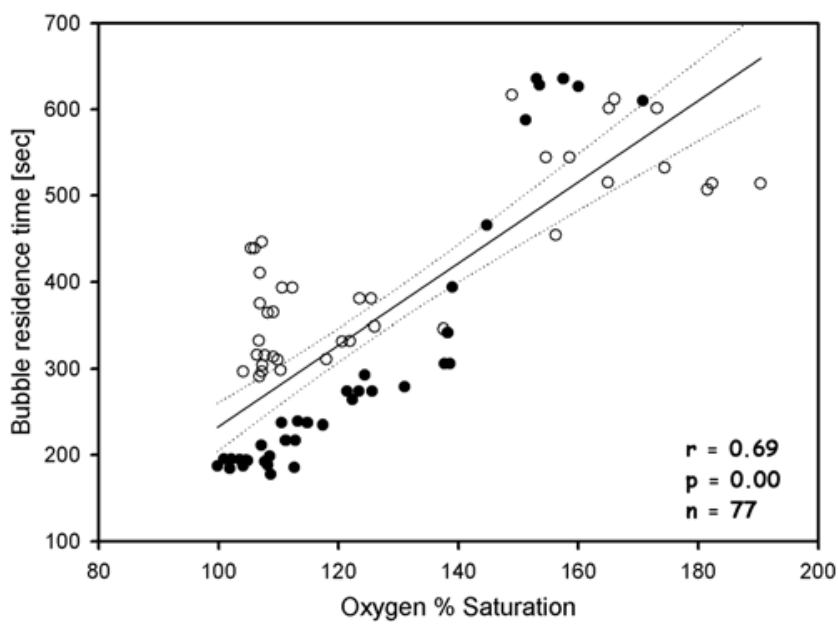

Figure 6. Oxygen saturation versus BRT for the Kiel Firth water growth experiment. Black solid line = linear regression; black dotted lines $=95 \%$ confidence intervals; open symbols $=$ data points during oxygen saturation increase; filled symbols = data points during oxygen saturation decline. 


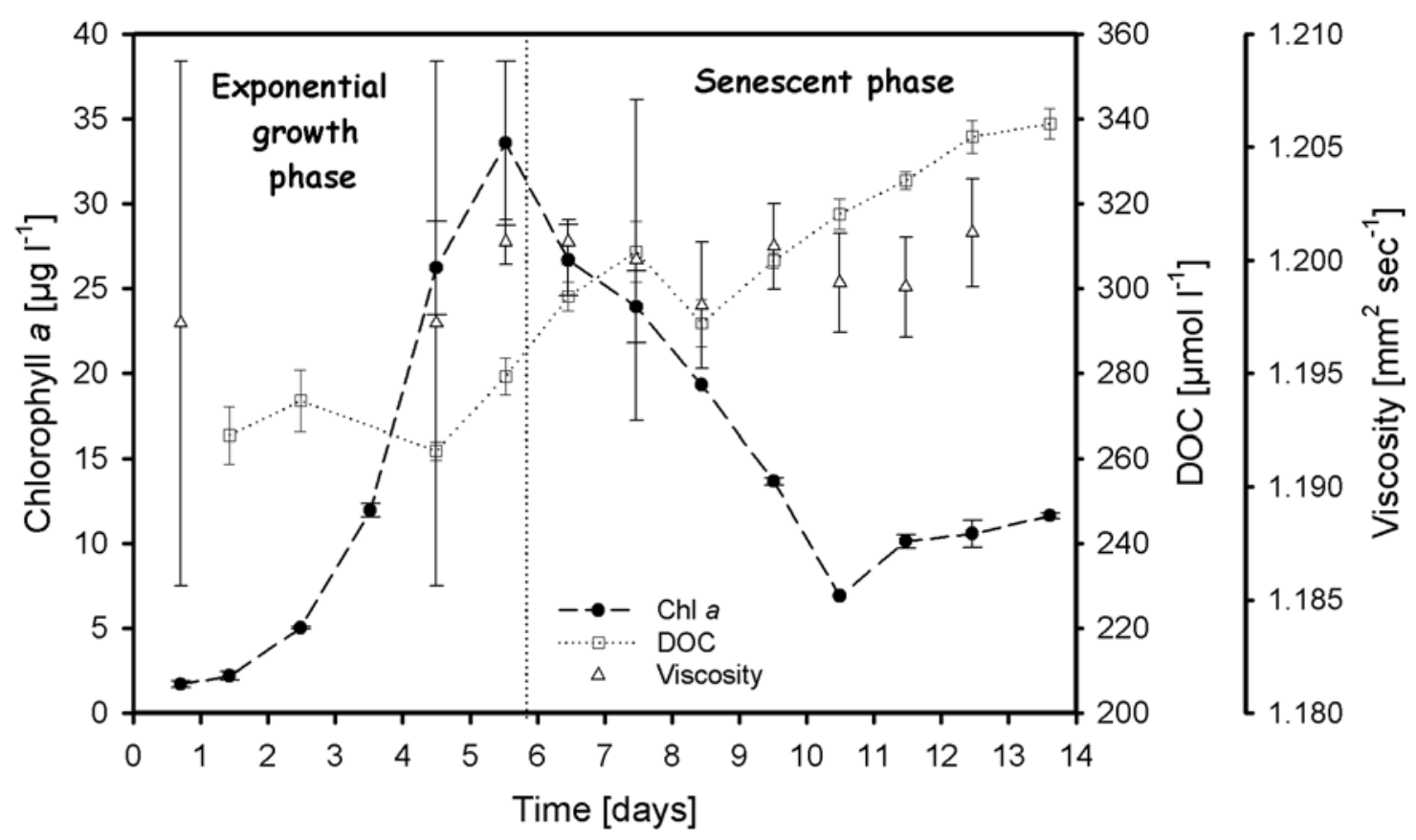

Figure 7. Changes in chlorophyll $a$ concentration, DOC and viscosity with time for the Kiel Firth water growth experiment. DOC error bars: $\pm 0.2-11 \mu \mathrm{mol} \mathrm{l}^{-1}$, chlorophyll error bars $\pm 0.2-2.8 \mu \mathrm{g} \mathrm{l}^{-1}$; viscosity error bars: $\pm 0.001-0.01 \mathrm{~mm}^{2} \mathrm{~s}^{-1}$. The vertical dotted line indicates change from exponential to senescent growth phase.

However, the diatom population was not limited by inorganic nutrient availability throughout the experiment.

[28] Chlorophyll concentration declined from an initial value of $21 \mu \mathrm{g} \mathrm{l}^{-1}$ to about $10 \mu \mathrm{g}^{-1}$ between days 1.5 and 2.5 (Figure 8) due to sedimentation of some cells onto the base of the tank. From day 2.5 to 9.5 , the chlorophyll concentration increased to $24 \mu \mathrm{g}^{-1}$ and between days 9.5 and 12.5 , chlorophyll concentration remained fairly constant at approximately $25 \mu \mathrm{g}^{-1}( \pm 2)$. A drop in chlorophyll concentration to $17.4 \mu \mathrm{g} \mathrm{l}^{-1}( \pm 1)$ occurred on day 13.5 followed by a further increase to $23 \mu \mathrm{g} \mathrm{l^{-1 }}$ on day 14.5. Chlorophyll concentration began to decline from day 16.5 reaching a value of $1.4 \mu \mathrm{g} \mathrm{l}^{-1}$ on day 21.5.

[29] Oxygen saturation measured (21-23 times per day) by the electrode and Winkler oxygen data showed close agreement (Figure 8). Before the addition of nutrients and diatom culture, oxygen saturation of filtered North Sea water was $96 \%$ between days 0.5 and 1.5 . Shortly after the addition of nutrients and the Cylindrotheca closterium culture (from day 2.5), oxygen saturation began to increase, showing distinct light phase increases and dark phase decreases (Figure 8). Between days 2.0 and 6.5, oxygen saturation increased from $96 \%$ to a maximum of $150 \%$ with up to $22 \%$ increase during the light phase and $11 \%$ decrease during the dark phase. Saturation remained constant during days $6.5-11.5$ (maximum of $150 \%$ during light phase, minimum of $132 \%$ during dark phase). Between days 11.5-12.5, when the tank illumination was switched off for a period of $24 \mathrm{~h}$ in error, oxygen saturation decreased from $150 \%$ to $118 \%$. Between days $12.5-13.5$, when the tank system was illuminated for $24 \mathrm{~h}$, saturation increased again to142\%. From days 13.5 to 16.5 (again 12/12 h light dark cycle), oxygen saturation declined slightly from a maximum of $142 \%$ to $135 \%$, still showing distinct light-dark changes. From day 17.5, the light/dark changes became much smaller until they ceased completely from days 18.0 to 23.5 , when saturation declined to a minimum of $63 \%$.

[30] Following the filling of the tank with filtered North Sea water on day 0.5 , BRT decreased from 240 to $220 \mathrm{~s}$ during the first day (Figure 8). Then with the addition of algae and nutrient medium, BRT stabilized at about $220 \mathrm{~s}$. With increasing chlorophyll concentration and oxygen saturation, BRT increased consistently from 220 to $350 \mathrm{~s}$ on day 5.5. From days 4.0 to 18.0, BRT showed distinct lightdark fluctuations with increases during light periods, when the oxygen saturation also increased, and decreases during darkness, when the saturation decreased. Differences in the BRT values between dark phase and light phase were about $80 \mathrm{~s}$ at the chlorophyll and oxygen saturation maximum ( $\sim 25 \mu \mathrm{g}^{-1}$ and $150 \%$ respectively) during days 8.0 to 12.0 , when BRT reached maximum values of $420 \mathrm{~s}$ during light phase. On days 11.5 and 12.5 , when the light dark cycle was changed to $24 \mathrm{~h}$, the strong decrease in oxygen saturation during dark phase $(150-117 \%)$ co-varied with a strong decline in BRT from 400 to $225 \mathrm{~s}$. During the following $24 \mathrm{~h}$ light phase, the increase in oxygen saturation was accompanied by an increase in BRT to $400 \mathrm{~s}$ by the end of the light phase. From days 14.0-17.0, both oxygen saturation and BRT declined slightly, however, the light dark fluctuations were still clearly visible until day 18.0. Between days 18.0 and 23.5, when chlorophyll concentration and oxygen saturation declined rapidly, BRT decreased to a mean value of approximately $170 \mathrm{~s}$.

[31] Chlorophyll concentration and daily mean BRT were highly correlated $(r=0.76, p$-value $=0.00$ and $n=21)$ and Figure 9 shows a clear linear relationship. BRT and oxygen 


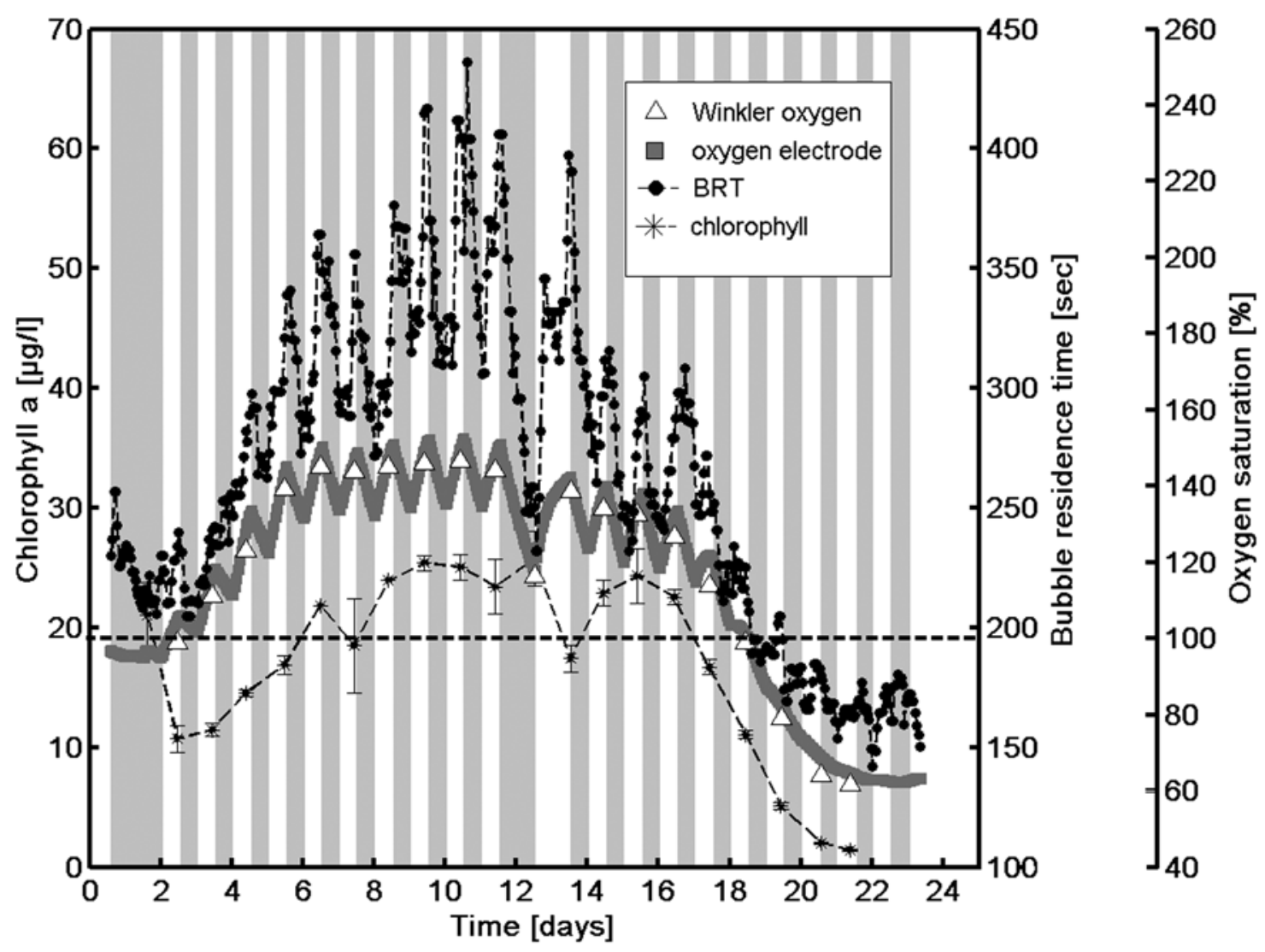

Figure 8. Changes in chlorophyll $a$ concentration, BRT and oxygen saturation with time for the growth experiment with Cylindrotheca closterium. The grey shaded bars indicate periods when the tank illumination was switched off, the white bars indicate the times when the tank system was illuminated. The black dashed line indicates the $100 \%$ oxygen saturation threshold.

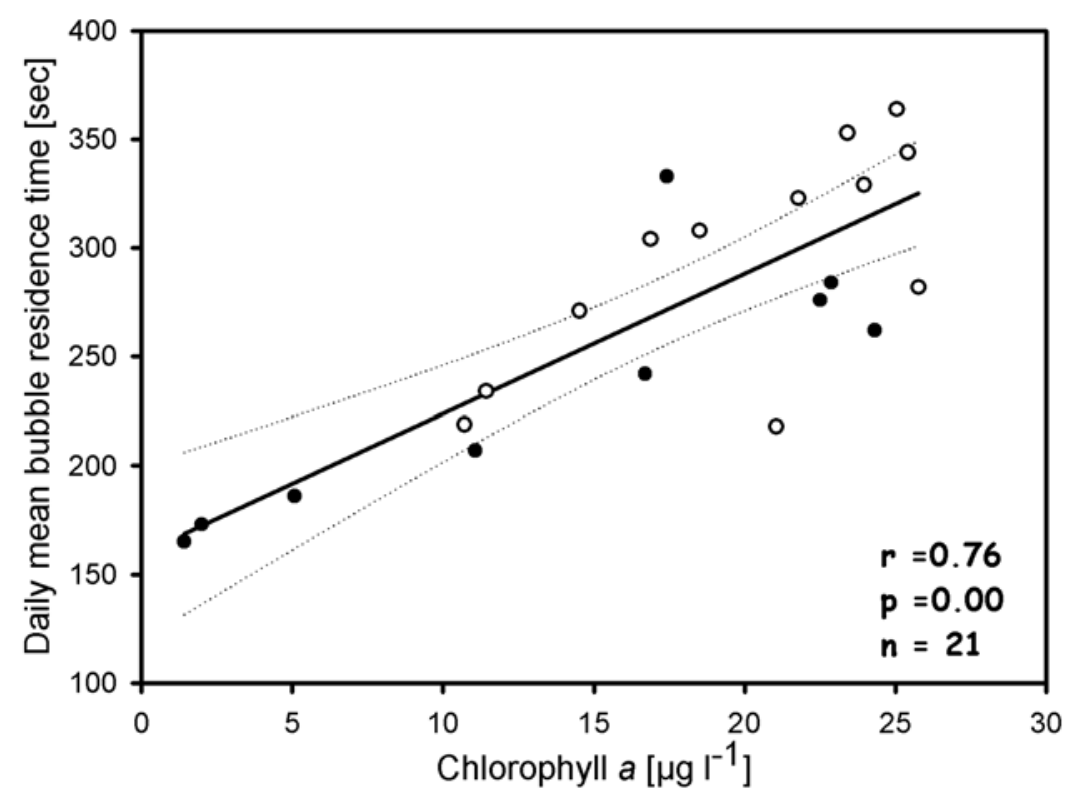

Figure 9. Chlorophyll $a$ concentration versus mean daily BRT for the Cylindrotheca closterium growth experiment. Black solid line $=$ linear regression; black dotted lines $=95 \%$ confidence intervals; open symbols = data points during chlorophyll increase; filled symbols $=$ data points during chlorophyll decrease. Averaging intervals were between 21-23 BRT measurement points depending on the number of measurements made per day. 


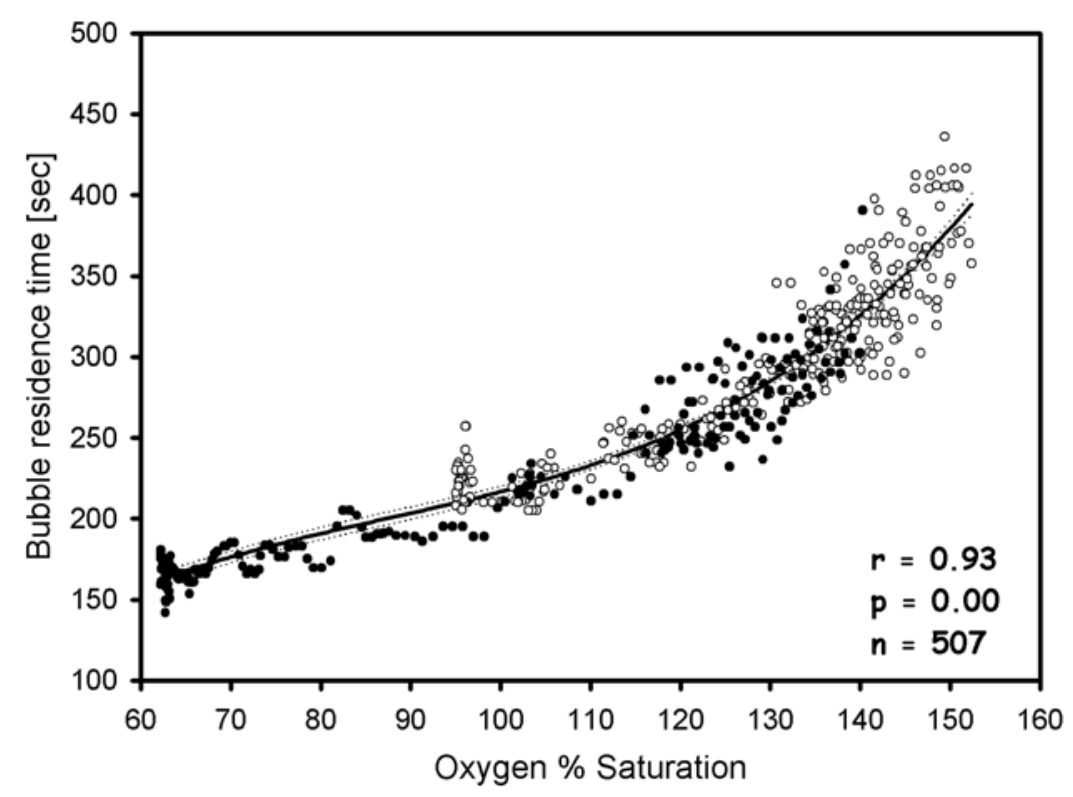

Figure 10. Oxygen saturation versus BRT for the Cylindrotheca closterium growth experiment. Black solid line $=$ quadratic regression; black dotted lines $=95 \%$ confidence intervals; open symbols $=$ data points during oxygen saturation increase; filled symbols = data points during oxygen saturation decline.

saturation also showed a strong correlation (Figure 10; $\mathrm{r}=$ 0.93, $\mathrm{p}$-value $=0.00$ and $\mathrm{n}=507)$.

[32] DOC values did not change significantly during the exponential growth phase $\left(\sim 135 \mu \mathrm{mol} 1^{-1}\right.$; Figure 11$)$ but during the stationary phase (days 7.0-17.0), DOC increased to $195 \mu \mathrm{mol} \mathrm{1}^{-1}$ and continued to increase during the senescent phase of the culture (days 17.0-21.5) to $245 \mu \mathrm{mol}$ $1^{-1}$. Bulk water viscosity showed some increase $\left(0.905 \mathrm{~mm}^{2}\right.$ $\mathrm{s}^{-1}$ to $0.910 \mathrm{~mm}^{2} \mathrm{~s}^{-1}$ ) during the exponential growth phase between days 1.5 and 7.0, when the chlorophyll concentration increased (Figure 11). A further increase in viscosity occurred between days 7 and 13 (increase to $0.915 \mathrm{~mm}^{2} \mathrm{~s}^{-1}$ ), however, the range of measured viscosity values was very small $\left(0.905 \mathrm{~mm}^{2} \mathrm{~s}^{-1}-0.915 \mathrm{~mm}^{2} \mathrm{~s}^{-1}\right)$ and the standard deviation large compared to the small range of values $\left( \pm 0.0018-0.0082 \mathrm{~mm}^{2} \mathrm{~s}^{-1}\right)$.

[33] No apparent co-variation between the total bacteria concentration and BRT was evident. The total bacteria number per $\mathrm{ml}$ in the tank water increased between days 1.5 and 5.5 from $3.4 \times 10^{6}$ to $9.3 \times 10^{6}$ cells $\mathrm{ml}^{-1}$, followed by a decrease between days 6.5 and 8.5 to $1.2 \times$ $10^{6}$ cells $\mathrm{ml}^{-1}$. From day 9.5 to day 13.5 , the total bacteria

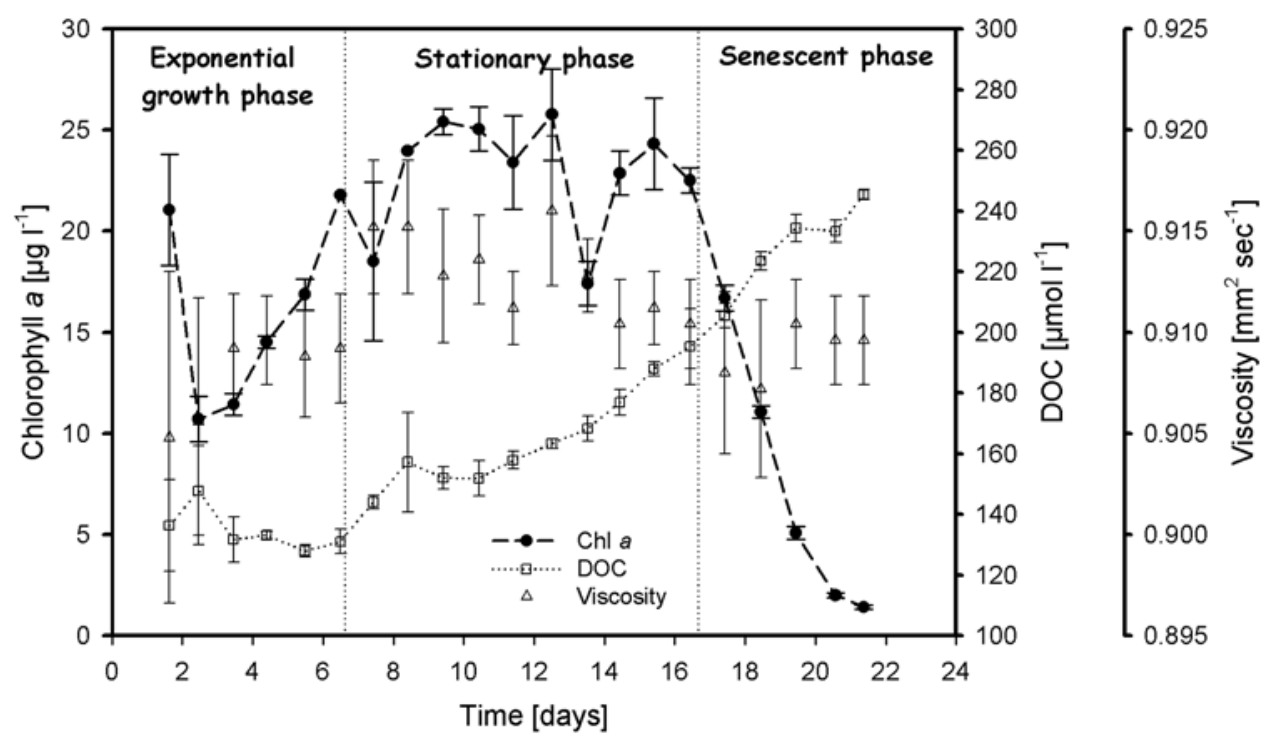

Figure 11. Changes in chlorophyll $a$ concentration, DOC and viscosity with time for the Cylindrotheca closterium growth experiment. DOC error bars: $\pm 1.4-16.4 \mu \mathrm{mol} \mathrm{l}^{-1}$, chlorophyll error bars $\pm 0.1-2.7 \mu \mathrm{g}$ $1^{-1}$; viscosity error bars: $\pm 0.0018-0.0082 \mathrm{~mm}^{2} \mathrm{~s}^{-1}$. The vertical dotted lines indicate changes from exponential to stationary to senescent growth phases. 


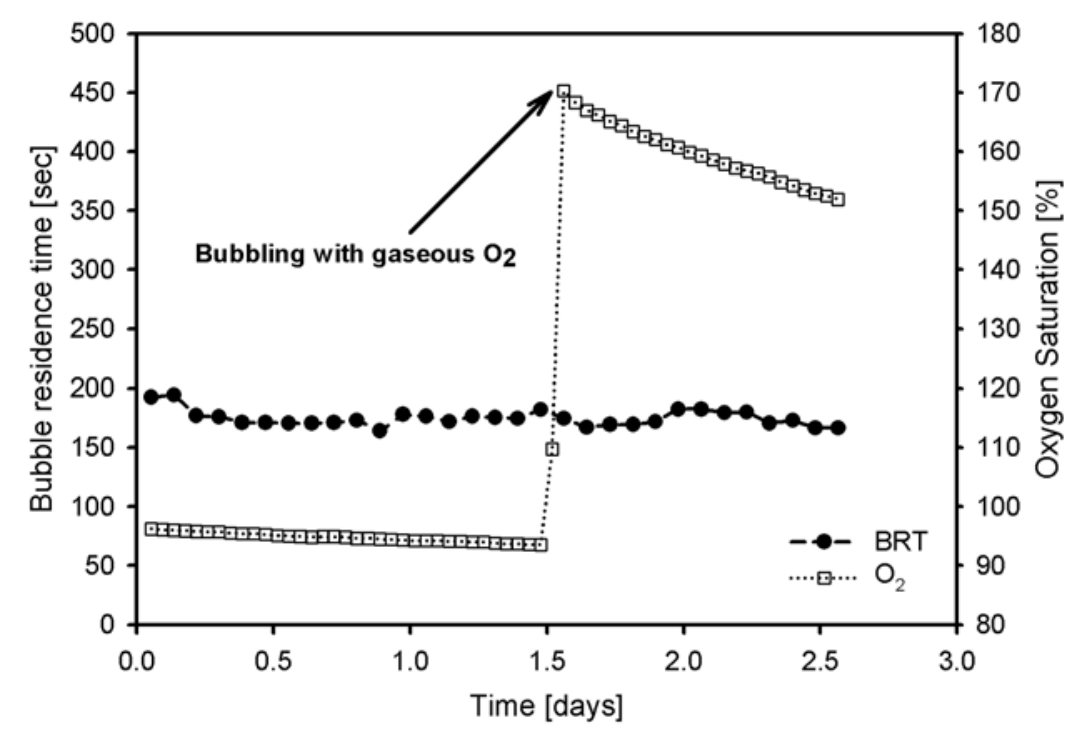

Figure 12. Changes in bubble residence time and oxygen saturation during the control saturation experiment using deionized water.

number increased to $5.5 \times 10^{6}$ cells $\mathrm{ml}^{-1}$. Between days 15.5 and 18.5 , a further increase to $9.8 \times 10^{6}$ cells ml $^{-1}$ was followed by another decline (days 19.5 and 20.5) to $3.6 \times$ $10^{6}$ cells $\mathrm{ml}^{-1}$. The average standard deviation of total bacteria counts was $\sim \pm 25 \%$.

\subsection{Oxygen Supersaturation of Deionized Water}

[34] Results from the phytoplankton growth experiments described in the previous sections suggest that the main influence on BRT appears to be the degree of oxygen saturation of the water as a result of phytoplankton photosynthesis. The amount of organic exudates seem to have little or no direct effect on BRT as no correlation was evident between DOC concentration and BRT. To verify the influence of oxygen saturation on BRT, the oxygen saturation of water in the absence of growing phytoplankton was physically manipulated. The bubbling of deionized water with pure oxygen for 2 min on day 1.5 resulted in an oxygen supersaturation of $170 \%$ (Figure 12), which then gradually declined over the following 2 days. However, no significant change in BRT occurred, while the water was highly supersaturated with oxygen and average BRT remained at approximately $180 \mathrm{~s}$ throughout the experiment.

\subsection{Model Dissolved Organic Substance-Xanthan Gum}

[35] As shown by the results of the previous experiment, oxygen supersaturation on its own was not the dominant factor causing the observed increases in BRT during the phytoplankton growth experiments with a natural phytoplankton population from Kiel Firth water and a Cylindrotheca closterium culture. Therefore it was investigated whether deionized water artificially enriched with a polysaccharide compound could have (i) an effect on the bulk water viscosity and (ii) an effect on BRT. Additionally, both oxygen saturation and concentration of the model polysaccharide were enhanced and the effect on BRT investigated.

[36] The average BRT of deionized water was approximately $140 \mathrm{~s}$, while oxygen saturation gradually increased from $55 \%$ to $70 \%$ within the first 4.5 days of the experiment
(Figure 13). Kinematic viscosity was $0.868 \mathrm{~mm}^{2} \mathrm{~s}^{-1}$. With the addition of Xanthan Gum to a concentration of $0.008 \mathrm{~g}$ $1^{-1}$ on day 4.6 , kinematic viscosity increased slightly to $0.900 \mathrm{~mm}^{2} \mathrm{~s}^{-1}$, however, no detectable increase in BRT occurred. On day 5.68, oxygen saturation was increased by bubbling with oxygen from a pressure bottle to $142 \%$, however, BRT showed only a very slight increase to $160 \mathrm{~s}$. The addition of Xanthan Gum to a concentration of $0.08 \mathrm{~g}$ $1^{-1}$ on day 5.72 however resulted in an increase in viscosity to $1.272 \mathrm{~mm}^{2} \mathrm{~s}^{-1}$ and an increase in BRT to $\sim 280 \mathrm{~s}$. For the remaining period of the experiment, BRT, oxygen saturation as well as bulk water viscosity gradually declined.

\section{Discussion}

4.1. Air Bubble Residence Time in Relation to the Phytoplankton Growth Related Parameters Chlorophyll Concentration and Oxygen Saturation

[37] A significant correlation was found between chlorophyll concentration, oxygen saturation and bubble residence time for both phytoplankton growth experiments. During both experiments BRT increased simultaneously with increasing chlorophyll concentration and thus, increasing oxygen saturation. However, the experiments differ significantly with respect to the order of magnitude of initial and maximum chlorophyll concentration, oxygen saturation and BRT, as is summarized in Table 1 . The maximum chlorophyll concentrations reached in both growth experiments were high in comparison to those typically measured in coastal waters. Osterroth et al. [1985] reported chlorophyll $a$ concentrations during the spring bloom in Kiel Bight of 1982 to have reached $5-17 \mu \mathrm{g} \mathrm{l}^{-1}$ and during autumn blooms, chlorophyll $a$ ranged between $10-20 \mu \mathrm{g} 1^{-1}$. However, in highly eutrophic regions of the Baltic Sea, mean levels during spring 2004 averaged around $114 \mu \mathrm{g} \mathrm{l^{-1 }}$ [Schumann et al., 2005].

[38] Despite an initial lower chlorophyll concentration, higher maximum chlorophyll concentrations, oxygen saturation and BRT values were reached during the Kiel Firth water experiment than during the experiment with the 


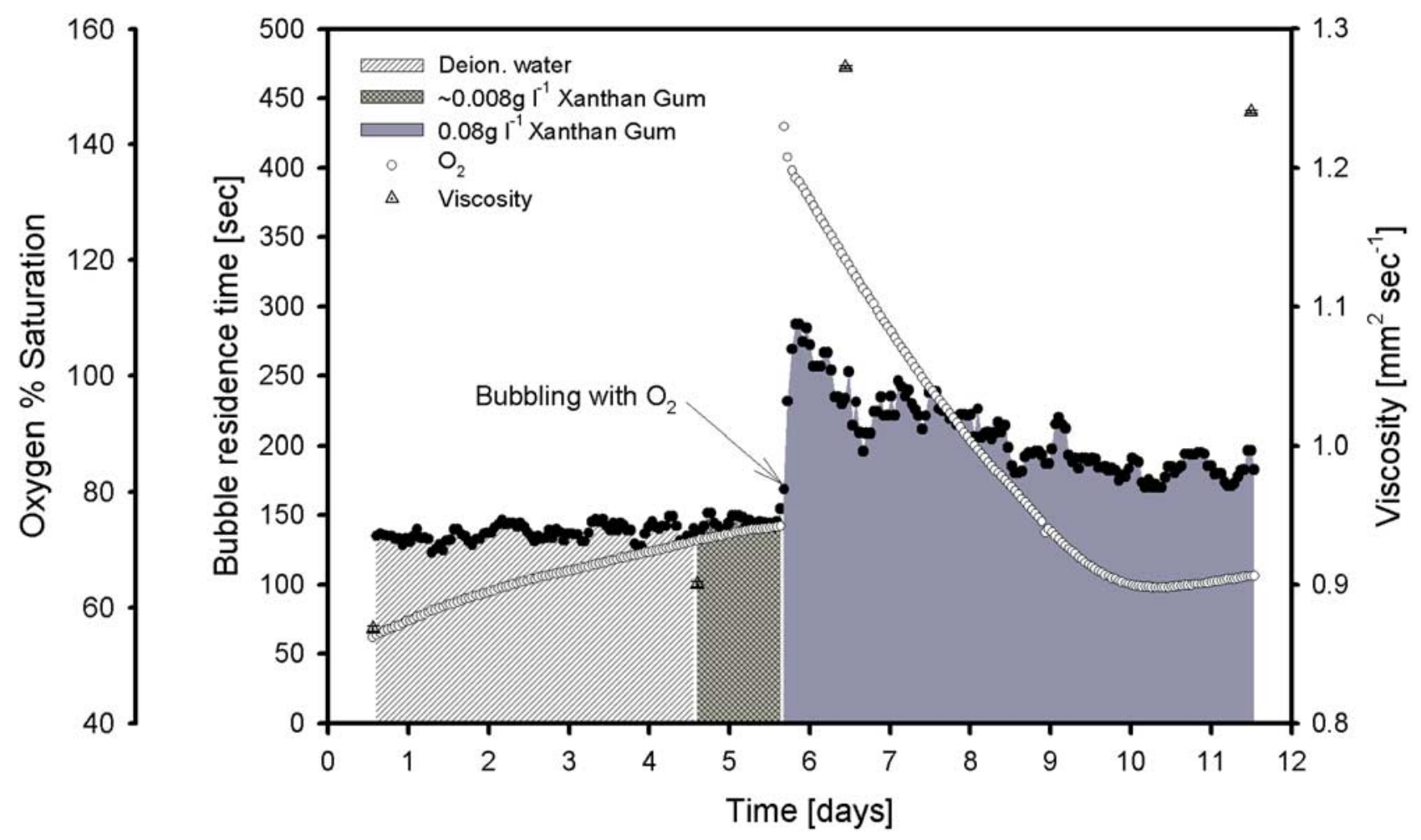

Figure 13. Changes in bubble residence time (black symbols), oxygen saturation and viscosity with time for different concentrations of Xanthan Gum and oxygen saturation.

culture of Cylindrotheca closterium. Reasons for the variation in the maxima of these parameters may be explained by the different species compositions for the two experiments.

[39] The close covariation between chlorophyll concentration and BRT for both growth experiments and the strong correlation between chlorophyll concentration and BRT for the Cylindrotheca closterium experiment suggest that increases in BRT may be linked to increases in the number of particles present in the tank system. However, data from other phytoplankton growth experiments using the tank system (not included here) have shown that despite high chlorophyll levels of up to $70 \mu \mathrm{g} 1^{-1}$, no major change in BRT occurred if the water remained undersaturated with respect to oxygen [Kuhnhenn-Dauben, 2005]. Thus it is likely that the increasing particle concentrations represented by increases in chlorophyll concentration were a co-factor causing increased BRT, possibly by means of a reduction in bubble rise velocity as has been described by Thorpe [1982] and Patro et al. [2001] via their accumulation on the surfaces of the bubbles [Kepkay, 1994; Slauenwhite and Johnson, 1996; Patro et al., 2001].

[40] It is also possible that the phytoplankton were acting as bubble nucleation sites and when the tank was supersaturated with respect to oxygen, a large number of small bubbles with low rise velocities may have formed about the phytoplankton particles, giving rise to the longer BRTs observed during the growth experiments. This may also be the reason why no increases in BRT were observed in the absence of phytoplankton particles during the oxygen supersaturation control experiment with deionized water.

[41] The data from the two growth experiments show that a certain threshold in oxygen saturation must be reached before major changes in BRT become apparent (Figures 4 and 8); this threshold being around $110 \%$. A similar saturation threshold was reported by Bowyer [1992] and Keeling [1993] to be linked to the dissolution of small bubbles, which is in turn dependent on the level of gas saturation and its influence on the stable existence, growth

Table 1. Initial (Beginning of Growth Phase) and Maximum (Following Growth Phase) Chlorophyll $a$ Concentration, BRT and Oxygen Saturation for Both Growth Experiments

\begin{tabular}{lll}
\hline & Kiel Firth Water & Cylindrotheca Closterium \\
\hline Initial chl $a$ concentration, $\mu \mathrm{g} \mathrm{1}^{-1}$ & 1.7 (day 0.5) & 10.7 (day 2.5) \\
Maximum chl $a$ concentration, $\mu \mathrm{g} \mathrm{1^{-1 }}$ & $33.6($ day 5.5) & 25.5 (day 9.5) \\
Initial BRT, s & $\sim 400($ day 0.5$)$ & $219($ day 2.5$)$ \\
Maximum BRT, s & $620($ day 5.5) & $400($ day 9.5$)$ \\
Initial oxygen saturation, \% & 102.8 (day 0.5) & $104($ day 2.5) \\
Maximum oxygen saturation, \% & 190 (day 5.5) & $150($ day 9.5) \\
\hline
\end{tabular}


Table 2. Total Gas Pressure of Tank Water, Laplace Pressure and Total Bubble Pressure for Bubbles at and Close to Resonance ${ }^{a}$

\begin{tabular}{ccc}
\hline \hline $\begin{array}{c}\text { Oxygen } \\
\text { Saturation, \% }\end{array}$ & Pressure, Pa \\
\hline 100 & 101325 & \\
110 & 103352 & \\
120 & 105378 & \\
130 & 107405 & \\
140 & 109431 & \\
160 & 113484 & \\
180 & 117537 & \\
190 & 119564 & \\
\hline \multicolumn{4}{c}{$\mathrm{r}=40 \mu \mathrm{m}$} \\
\hline $\mathrm{r}=20 \mu \mathrm{m}$ & $\mathrm{r}=30 \mu \mathrm{m}$ \\
\hline 7300 & 4866 & 115060 \\
\hline \multicolumn{4}{c}{ Laplace Pressure, Pa } \\
\hline \hline
\end{tabular}

${ }^{a}$ Total bubble pressure was calculated after Woolf and Thorpe [1991]. The total gas pressure was calculated estimating a constant partial pressure of nitrogen of 0.8 atmospheres. $r$ is the bubble radius.

or disappearance of bubbles in near surface waters [Ramsey, 1962; Harris and Detsch, 1991]. Bubbles lose gas by dissolution when the internal bubble pressure exceeds the total gas pressure in the water and they tend to gain gas when the opposite is true. Bowyer [1992] and Stramska et al. [1990] report that for increasing saturation of water with dissolved gas (in this case, oxygen), the smallest bubbles that can exist show a tendency toward a lower radius. Table 2 provides an estimate of the theoretical gas pressure in the tank water with increasing oxygen saturation as well as the Laplace pressures and total bubble pressures of bubbles at and close to resonance for a frequency of $120 \mathrm{kHz}$ [Vagle and Farmer, 1992] calculated after Woolf and Thorpe [1991]:

$$
\Sigma p_{b}=P_{a}+\rho_{w} \cdot g \cdot z+2 \sigma / r
$$

where $p_{b}$ is the total pressure inside the bubble, $P_{a}$ is the atmospheric pressure $(101325 \mathrm{~Pa}), \rho_{w}$ is the density of seawater $\left(\sim 1028 \mathrm{~kg} \mathrm{~m}^{-3}\right), g=9.81 \mathrm{~m} \mathrm{~s}^{-2}, z$ is the maximum depth of bubble plume $(1 \mathrm{~m}), \sigma$ is the bubble surface tension $\left(\sim 73 \mathrm{mN} \mathrm{m}^{-1}\right)$ and $r$ is the bubble radius.

[42] This calculation was made assuming constant nitrogen saturation in the tank water although it is possible that the nitrogen saturation also changed during phytoplankton growth. Even at high oxygen supersaturations of 160 $180 \%$, resonant bubbles (radius $=20 \mu \mathrm{m}$ for $120 \mathrm{kHz}$ ) and those close to resonance $(r=15-40 \mu \mathrm{m})$ were still not in equilibrium with the surrounding water, a condition that Woolf and Thorpe [1991] have reported as normal due to hydrostatic pressure and surface curvature of bubbles. As the total gas pressure in the bubbles at $1 \mathrm{~m}$ depth exceeds the gas pressure of the surrounding water, diffusion of gas should still take place from the bubbles into the water. However, at first, the process is decelerated with increasing oxygen saturation, thus bubbles dissolve more slowly, resulting in longer residence times. Secondly, some gases compressed inside a bubble are much more soluble than others (e.g., $\mathrm{CO}_{2}$ ) and will equilibrate more rapidly, decelerating the net flux of gas [Woolf and Thorpe, 1991] and thus bubble dissolution. For microbubbles in deeper layers, dissolution may occur much faster (e.g., $z=1.5 \mathrm{~m}$ ), whereas microbubbles in the near surface layer may dissolve even more slowly (e.g., $z=0.5 \mathrm{~m}$ ). As the bubbles rise through the water column, the decrease in hydrostatic pressure will also lead to a reduction in total bubble pressure and thus decelerate dissolution [Bowyer and Woolf, 2004].

[43] In both microalgal growth experiments there were periods when phytoplankton photosynthesis during light phases increased the oxygen saturation and respiration during dark phases decreased the oxygen saturation in the tank water. These periods of increase and decrease in $\mathrm{O}_{2}$ saturation coincided with similar relative changes in BRT. This coincidence was very clearly apparent during most of the growth experiment with Cylindrotheca closterium but less apparent during the experiment with Kiel Firth water with coincidence only noticeable during days $1.5-4.5$ and days 8.5-11.0 (Figure 4). Assuming that oxygen saturation was the dominant factor responsible for the observed changes in BRT during light and dark phase in the Cylindrotheca closterium growth experiment, it is perhaps surprising that these differences are much less obvious throughout the Kiel Firth water experiment. One explanation for this could be the considerably higher oxygen saturations reached during the Kiel Firth water experiment (up to 190\%) compared to the Cylindrotheca closterium experiment (up to $150 \%$ ). This would imply that oxygen saturation had reached a level between day 4.5 and 8.5 where even during dark phases the oxygen saturation was high enough for the smallest bubbles not to attain dissolution. Another factor that may account for the less obvious light and dark changes in BRT during the chlorophyll maximum of the Kiel Firth water experiment is the difference in salinity of the water used in both experiments (31 for Cylindrotheca closterium culture water and 16 for Kiel Firth water). The growth of the diatom Cylindrotheca closterium in higher salinity water may have resulted in slightly different (i.e., smaller) bubble sizes as a result of reduced coalescence [Craig et al., 1993; Wang and Monahan, 1995]. In turn, smaller bubbles may have been more sensitive to the degree of oxygen saturation compared to slightly larger bubbles and therefore they may have dissolved earlier, especially when the oxygen saturation was slightly lower. As the set-up of the tank system and the methodology of BRT determination did not allow for bubbles to be optically monitored, information on their abundance, size and dissolution is unavailable.

[44] The experimental data from the phytoplankton growth experiments as well as the argument for the importance of gas/oxygen saturation with respect to bubble dissolution and bubble growth supported by other authors at first suggests oxygen saturation as the main factor responsible for the observed increases and decreases in BRT over a phytoplankton growth period.

[45] However, supersaturating deionized water with oxygen from a pressurized bottle showed that oxygen saturation alone may not have been the main cause of the observed changes in BRT during phytoplankton growth. This artificial supersaturation did not coincide with a change in BRT, an unexpected result, as Stramska et al. [1990] and Asher and Farley [1995] have shown that increasing concentra- 
tions of dissolved gases resulted in higher bubble concentrations. However, the nitrogen saturation was not measured in our experiments and it may be that bubbling the tank water with oxygen resulted in most of the dissolved nitrogen being stripped out. The oxygen would thus have only replaced the nitrogen and not increased the total gas pressure of the tank water. Considering that bubble residence time is a function of the total gas pressure [Woolf and Thorpe, 1991], this could be an explanation why bubbling with oxygen did not result in increasing BRT. From the phytoplankton growth experiments it follows that sufficient saturation of water with oxygen is a precondition for major changes in BRT to occur as a result of the net diffusive flux of gases across the air bubble- water interface. This flux is proportional to the concentration gradient of a gas between water and the overlying air [Woolf and Thorpe, 1991]. Also Bowyer [1992] stated that for a certain degree of gas saturation, the initial radius of a bubble is important with respect to its lifetime. If this initial radius is below a certain threshold, the bubble will collapse immediately after formation as a result of the Laplace pressure. In order for bubbles not to dissolve immediately after their formation but to grow, gas must diffuse into the bubble from the surrounding water [Bowyer, 1992]. As the exchange of gas is always from high to low concentration, gas, respectively oxygen will diffuse into the bubble only if the water is supersaturated with oxygen. This will then result in stabilization and growth of the bubble, enabling it to reside in the water for a longer period of time. However, as stated by Bowyer and Woolf [2004] bubble gasdynamics are nonlinear, and interdependencies exist between the exchange of gas across a bubble's surface, its resulting size and further gas exchange.

\subsection{Dissolved Organic Material}

[46] A consistent covariation between BRT and DOC concentration was not shown in either phytoplankton growth experiments. For both growth experiments, DOC increased with increasing chlorophyll concentration, but the concentrations and rates of increase became significantly higher during the stationary and senescent phases. These results generally agree with the findings of other studies conducted by Lee and Wakeham [1989], Williams [1990], and Norrman et al. [1995], who also reported that DOC accumulation rates were higher during the senescent phase of a phytoplankton bloom compared to the exponential growth phase. The increase of DOC concentration during the senescent phase of the phytoplankton growth experiments may be attributed to nutrient stress as already discussed by Jensen [1984] and Williams [1990]. Bacterial induced cell lysis of phytoplankton cells during the senescent phase, described by Imai et al. [1993] as well as bacterial release of DOC from capsular material [Stoderegger and Herndl, 1998] were likely to have contributed to the higher DOC levels measured during senescent phases. However, despite the lack of a covariation between DOC concentration and BRT, it is highly likely that some fractions of the DOM released by phytoplankton throughout the growth experiments, influenced BRT to some extent. Diatoms can release large amounts of polysaccharides during all stages of growth, [Hoagland et al., 1993; Zutic et al., 1981; Mopper et al., 1995; Zhou et al., 1998] and some of these compounds are known to be surface active. In his investigations of algal mucilages, Leppard [1995] showed that the chemical composition determines the surface activity of DOM. Studies by Leppard [1995] and Lancelot [1995] indicate that a large fraction of the DOC produced by phytoplankton are reactive, surface active polysaccharides. It is highly likely that the chemical composition of DOC as well as its surface activity varies on a diurnal scale [Shinomura et al., 2005] as well as over the growth phase of a phytoplankton culture [Metaxatos et al., 2003] and additionally, is species specific [Mingazzini et al., 1995; Metaxatos et al., 2003]. This may also have been the case during the phytoplankton growth experiments with Kiel Firth water and Cylindrotheca closterium. It is possible, that during light periods, the DOC produced by the phytoplankton was more surface active than during dark periods, thus contributing to the diurnal variation in BRT. Furthermore, the DOC produced during the senescent phase may have been less surface active than during the exponential growth phase and combined with decreasing oxygen saturation may have led to a reduction in BRT, even though the overall DOC concentration increased during the later phases of the culture. The presence of organic surfactants released by phytoplankton has a significant influence on the state of the bubbles' surfaces, affecting the diffusion of gas and particles to and from the bubbles, as well as their rise speed and their surface tension [Detwiler, 1979; Woolf and Thorpe, 1991; Thorpe et al., 1992; Slauenwhite and Johnson, 1996; Leifer et al., 2000]. This could explain why initial BRT at the beginning of the phytoplankton growth experiments were higher than BRT in the deionized water, as bubbles in deionized water rose like clean bubbles [Woolf and Thorpe, 1991], whereas bubbles in the water containing phytoplankton rose like dirty bubbles. Unfortunately, rise speed of bubbles could not be measured with the experimental set-up. However, Thorpe [1982] states that the rise speeds of dirty bubbles of $\mathrm{r} \leq 80 \mu \mathrm{m}$ are closely proportional to $r^{2}$. Thus a $20 \mu \mathrm{m}$ bubble would rise approximately $0.04 \mathrm{~cm} \mathrm{~s}^{-1}$ and take $2500 \mathrm{~s}$ to rise to the tank surface from a depth of $1 \mathrm{~m}$. As BRTs in the phytoplankton growth experiments are much shorter, dissolution must be the dominant process.

\subsection{Bulk Water- and Surface Shear Viscosity}

[47] The range of bulk water viscosity values showed differences between the two growth experiments, which mainly resulted from the difference in water temperature and salinity. However, species specific differences may have also influenced the viscosity such as the nature of the organic material released by phytoplankton cells as well as the density and nature of the cells themselves. Species specific differences of bulk water viscosity also with respect to different water temperatures have been identified by Myklestad [1972] and Petkov and Bratkova [1996]. However, as no significant change in bulk water viscosity was detected over the duration of the Kiel Firth water experiment, and also not with certainty over the growth phase of the Cylindrotheca closterium experiment, it is unlikely that this factor had a major influence on BRT.

[48] The experiment with the model polysaccharide Xanthan Gum showed that a large change in bulk water viscosity can affect BRT. The polysaccharide concentrations used during the experiment were however highly exagger- 
ated compared to natural DOM concentrations in seawater. This suggests that the concentrations of organic material produced in the phytoplankton growth experiments were too low to have a measurable effect on bulk water viscosity. Investigations recently carried out by Kuhnhenn et al. [2006] have shown that some phytoplankton species can have a significant influence on the surface shear viscosity. They showed that the diatom Cylindrotheca closterium, a species which occurred in both growth experiments included in this study, had a marked effect on measured surface shear viscosity whereas a number of other diatom species tested showed no effect on surface shear viscosity. Kuhnhenn et al. [2006] found that Cylindrotheca closterium particularly influenced measured surface shear viscosity during the exponential growth phase of cultures. This supports the assumption made earlier that the surface-active nature of organic material released by phytoplankton varies over different stages of the growth curve. It also corresponds well with the strong increase in BRT, which occurred during the exponential growth phase for both phytoplankton growth experiments.

[49] Unfortunately, our experimental set-up did not provide a direct way of investigating the influence of surface shear viscosity on BRT. However, the relationship between surface shear viscosity and BRT could be explained as follows. Increased surface shear viscosity could have led to a decrease in bubble coalescence as a result of the mechanical resistance at the bubbles surface. This in turn would have resulted in longer residence times at high oxygen supersaturation (when small bubbles did not dissolve immediately), as smaller bubbles rise more slowly than larger bubbles. The formation of a rigid cap on the surface of the bubbles, resulting from compact mechanical structures as described by Dukhin et al. [1998] would have led to essential deceleration of the bubble rise velocities, thus contributing to increasing BRT. Furthermore, the formation of polymer networks on the surface of the bubbles possibly reduced the diffusion of gas from bubbles into the surrounding water.

\section{Conclusions}

[50] The results of this study have shown that phytoplankton growth can have a significant influence on air bubble residence time in seawater. The parameter that was directly influenced by phytoplankton photosynthesis and that was identified as a necessary precondition for major changes of BRT was the oxygen saturation of the water. Furthermore, during the course of growth experiments, changes in BRT closely corresponded with the photosynthesis-respiration (light-dark cycle) induced changes in oxygen saturation, for oxygen saturations below $150 \%$, emphasizing the dependency of BRT on the oxygen saturation of the water. The results of the saturation experiments with deionized water however indicate that oxygen supersaturation on its own in a non biological, particle-free system does not show any significant influence on BRT. Therefore it can be concluded, that a combination of factors including oxygen saturation as well as phytoplankton exudates were responsible for the increases and decreases in BRT observed during the phytoplankton growth experi- ments. The results from these experiments suggest that a certain threshold in oxygen saturation has to be achieved for major changes in BRT to occur, so that small bubbles do not dissolve immediately after their formation but can remain in the water for longer periods of time. This threshold was found to be between $110-140 \%$ oxygen saturation and is considered to be specific with respect to the species composition of the phytoplankton.

[51] Additionally, the actual phytoplankton cells and the organic material produced during blooms influence BRT, most likely through a change in bubble rise velocity and gas diffusion. Taking into account the results obtained by other authors, it is highly likely that some surface active material was produced during these experiments although it was not possible to directly characterize these compounds.

\section{Notation}

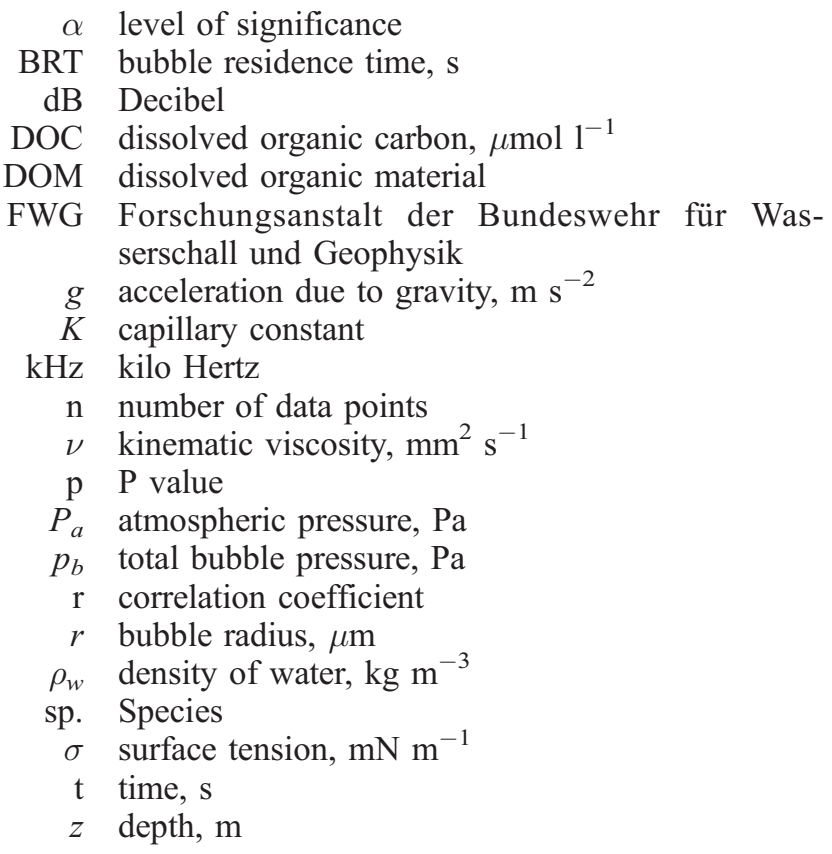

[52] Acknowledgments. The authors acknowledge the Federal Armed Forces Research Institute for Underwater Acoustics and Marine Geophysics for funding this research. The valuable comments of three referees helped to improve this manuscript.

\section{References}

Asher, W. E., and P. J. Farley (1995), Phase-Doppler anemometer measurement of bubble concentrations in laboratory-simulated breaking waves, J. Geophys. Res., 100, 7045-7056.

Asher, W. E., L. M. Karle, B. J. Higgins, P. J. Farley, E. C. Monahan, and I. S. Leifer (1996), The influence of bubble plumes on air-seawater gas transfer velocities, J. Geophys. Res., 101, 12,027-12,041.

Blanchard, D. C. (1963), The electrification of the atmosphere by particles from bubbles in the sea, Prog. Oceanogr., 1, 71-202.

Blanchard, D. C., and A. H. Woodcock (1957), Bubble formation and modification in the sea and its meteorological significance, Tellus, Ser. $A$ and Ser. B, 9, 145-158.

Bowyer, P. (1992), The rise of bubbles in a glass tube and the spectrum of bubbles produced by a splash, J. Mar. Res., 50, 521-543.

Bowyer, P., and D. K. Woolf (2004), Gas exchange and bubble induced supersaturation in a wind wave tank, J. Atmos. Oceanic Technol., 21, $1925-1935$

Craig, V. S. J., B. W. Ninham, and R. M. Pashley (1993), Effect of electrolytes on bubble coalescence, Nature, 364, 317-319. 
Deane, G. B., and M. D. Stokes (2002), Scale dependence of bubble creation mechanisms in breaking waves, Nature, 418, 839-844.

Detwiler, A. (1979), Surface active contamination of air bubbles in water, in Surface Contamination: Genesis, Detection and Control, edited by K. L. Mittal, pp. 993-1007, Plenum, New York.

Dukhin, S. S., R. Miller, and G. Loglio (1998), Physico-chemical hydrodynamics of rising bubble, in Drops and Bubbles in Interfacial Research edited by D. Möbius and R. Miller, pp. 367-432, Elsevier, Amsterdam.

Gershey, R. M. (1983), A bubble adsorption device for the isolation of surface active organic matter in seawater, Limnol. Oceanogr., 28, 395-400.

Graham, A., D. K. Woolf, and A. J. Hall (2004), Aeration due to breaking waves. Part I: Bubble populations, J. Phys. Oceanogr., 34, 989-1007.

Grasshoff, K., K. Kremling, and M. M. Erhard (Eds.) (1999), Methods of Seawater Analysis, 3rd Ed., 600 pp., Verlag Chemie, Weinheim.

Guillard, R. R. L., and J. H. Ryther (1962), Studies of marine planktonic diatoms. I. Cyclotella nana Hustedt and Detonula confervacea (Cleve), Can. J. Microbiol., 8, 229-239.

Harris, I. A., and R. M. Detsch (1991), Small air bubbles in reagent grade water and seawater-2. Dissolution of 20 - to $500 \mu \mathrm{m}$-diameter bubbles at atmospheric pressure, J. Geophys. Res., 96, 8907-8910.

Hoagland, K. D., J. R. Rosowski, M. R. Gretz, and S. C. Roemer (1993), Diatom extracellular polymeric substances: Function, fine structure, chemistry and physiology, J. Phycol., 29, 537-566.

Hobbie, J. E., R. J. Daley, and S. Jasper (1977), Use of nuclepore filters for counting bacteria by fluorescence microscopy, Appl. Environ. Microbiol., $33,1225-1228$

Hwang, P. A., Y.-K. Poon, and J. Wu (1991), Temperature effects on generation and entrainment of bubbles induced by a water jet, J. Phys Oceanogr., 21, 1602-1605.

Imai, I., Y. Ishida, and Y. Hata (1993), Killing of marine phytoplankton by a gliding bacterium Cytophaga sp., isolated from the coastal sea of Japan, Mar. Biol., 116, 527-532.

Jensen, A. (1984), Excretion of organic carbon as function of nutrient stress, in Marine Phytoplankton and Productivity, edited by O. HolmHansen, L. Bolis, and R. Gilles, pp. 61-72, Springer-Verlag, Berlin.

Keeling, R. F. (1993), On the role of large bubbles in air-sea gas exchange and supersaturation in the ocean, J. Mar. Res., 51, 237-271.

Kepkay, P. E. (1994), Particle aggregation and the biological reactivity of colloids, Ma. Ecol. Prog. Ser., 109, 293-304.

Kuhnhenn-Dauben, V. (2005), Phytoplankton induced changes of air bubble residence time in seawater, Ph.D., 217 pp., Univ. Southampton, Southampton, U. K

Kuhnhenn, V., J. Krägel, U. Horstmann, and R. Miller (2006), Surface shear rheological studies of marine phytoplankton cultures-Nitzschia closterium, Thalassiosira rotula, Thalassiosira punctigua and Phaeocystis sp. Colloids Surf. A and B, 47, 29-35.

Lancelot, C. (1995), The mucilage phenomenon in the continental coastal waters of the North Sea, Sci. Total Environ., 165, 83-102.

Lee, C., and S. G. Wakeham (1989), Organic matter in seawater: Biogeochemical processes, in Chemical Oceanography, vol. 9, edited by J. P. Riley, pp. 1-51, Academic Press, London.

Leifer, I., R. Patro, and P. Bowyer (2000), A study on the temperature variation of rise velocity for large clean bubbles, J. Atmos. Ocean. Tech. 17, $1392-1402$.

Leppard, G. G. (1995), The characterization of algal and microbial mucilages and their aggregates in aquatic ecosystems, Sci. Total Environ., 165 $103-131$

Merlivat, L., and L. Memery (1983), Gas exchange across an air-water interface: Experimental results and modelling of bubble contribution to transfer, J. Geophys. Res., 88, 707-724.

Metaxatos, A., C. Panagiotopoulos, and L. Ignatiades (2003), Monosaccharide and amino acid composition of mucilage material produced from a mixture of four phytoplanktonic taxa, J. Exp. Mar. Biol. Ecol., 294, $203-217$.

Mingazzini, M., S. Colombo, and G. M. Ferrari (1995), Application of spectrofluorometric techniques to the study of marine mucilages in the Adriatic Sea: Preliminary results, Sci. Total Environ., 165, 133-144.

Monahan, E. C., and H. G. Dam (2001), Bubbles: An estimate of their role in the global oceanic flux of carbon, J. Geophys. Res., 106, 9377-9383.

Mopper, K., J. Zhou, K. S. Ramana, U. Passow, H. G. Dam, and D. T. Drapeau (1995), The role of surface active carbohydrates in the flocculation of a diatom bloom in a mesocosm, Deep Sea Res., 42, 47-73.

Myklestad, S. M. (1972), Production of carbohydrates by the marine diatom Chaetoceros affinis var. willei (Gran) Hustedt. II. Preliminary investigation of the extracellular polysaccharide, J. Exp. Mar. Biol. Ecol., 9, 137-144.

Myklestad, S. M. (1995), Release of extracellular products by phytoplankton with special emphasis on polysaccharides, Sci. Total Environ., 165, $155-164$.
Nägeli, A., and F. Schanz (1991), The influence of extracellular algal products on the surface tension of water, Int. Rev. Gesamten Hydrobiol. $76,89-103$.

Nightingale, P. D., P. S. Liss (2004), Gases in seawater in Treatise on Geochemistry, vol. 6, The Oceans and Marine Geochemistry, edited by H. Elderfield, H. D. Holland, and K. K. Turekian, pp. 49-81, Elsevier, Amsterdam

Norrman, B., U. L. Zweifel, C. S. Hopkinson, and B. Fry (1995), Production and utilisation of dissolved organic carbon during an experimental diatom bloom, Limnol. Oceanogr., 40, 898-907.

Osterroth, C., A. Wenck, K. Kremling, and K. Gocke (1985), Concentration of dissolved organic copper in relation to other chemical and biological parameters in coastal Baltic water, Mar. Ecol. Prog. Ser., 22, 273-279.

Patro, R., I. Leifer, and P. Bowyer (2001), Better bubble process modelling: Improved bubble hydrodynamics parameterisation, in Gas Transfer and Water Surfaces, Geophys. Monogr. Ser., vol. 127, edited by M. Donelan et al., pp. 315-320, AGU, Washington, D.C.

Peltzer, R. D., and O. M. Griffin (1988), Stability of a three-dimensional foam layer in seawater, J. Geophys. Res., 93, 10,804-10,812.

Petkov, G. D., and S. G. Bratkova (1996), Viscosity of algal cultures and estimation of turbulency in devices for the mass culture of microalgae, Algol. Stud., 81, 99-104.

Ramsey, W. L. (1962), Dissolved oxygen in shallow near-shore water and its relation to possible bubble formation, Limnol. Oceanogr., 8, 453-461.

Revelante, N., and M. Gilmartin (1991), The phytoplankton composition and population enrichment in gelatinous macroaggregates in the Northern Adriatic during the summer of 1989, J. Exp. Mar. Biol. Ecol., 146, $217-$ 233 .

Sandler, B. M., D. A. Selivanovskii, and A. Yu. Selivanovskii (1982), New data on the concentration of gas bubbles with radii from 6 to $20 \mu \mathrm{m}$ in the sea, Sov. Phys. Tech. Phys., 27, 1038-1039.

Schumann, R., A. Hammer, S. Görs, and H. Schubert (2005), Winter and spring phytoplankton composition and production in a shallow eutrophic Baltic lagoon, Estuarine Coastal Shelf Sci., 62, 169-181.

Scott, J. C. (1975), The role of salt in whitecap persistence, Deep Sea Res., $22,651-657$.

Sharp, J. H. (1973), Size classes of organic carbon in seawater, Limnol. Oceanogr., 18, 441-447.

Shinomura, Y., T. Iwata, and Y. Suzuki (2005), Diel changes in dissolved organic carbon in the upper layer of Suruga Bay, Japan, Estuarine Coastal Shelf Sci., 62, 699-709.

Slauenwhite, D. E., and B. D. Johnson (1996), Effect of organic matter on bubble surface tension, J. Geophys. Res., 101, 3769-3774.

Stoderegger, K., and G. J. Herndl (1998), Production and release of bacterial capsular material and its subsequent utilization by marine bacterioplankton, Limnol. Oceanogr., 43, 877-884.

Stramska, M., R. Marks, and E. C. Monahan (1990), Bubble-mediated aerosol production as a consequence of wave breaking in supersaturated (hyperoxic) seawater, J. Geophys. Res., 95, 18,281-18,288.

Thorpe, S. A. (1982), On the clouds of bubbles formed by breaking windwaves in deep water, and their role in air-sea gas transfer, Philos. Trans. R. Soc. Ser. A and Ser. B, 304, 155-210.

Thorpe, S. A. (1986), Measurements with an automatically recording inverted echo sounder, ARIES and the bubble clouds, J. Phys. Oceanogr., $16,1462-1478$

Thorpe, S. A., and A. J. Hall (1987), Bubble clouds and temperature anomalies in the upper ocean, Nature, 328, 48-51.

Thorpe, S. A., P. Bowyer, and D. K. Woolf (1992), Some factors affecting the size distribution of oceanic bubbles, J. Phys. Oceanogr., 22, $382-$ 389.

Trevorrow, M. V., S. Vagle, and D. M. Farmer (1994), Acoustical measurements of microbubbles within ship wakes, J. Acoust. Soc. Am., 95, $1922-1930$

Utermöhl, H. (1958), Zur Vervollkommnung der quantitativen Phytoplankton-Methodik, Mitt. Int. Ver. Theor. Angew. Limnol., 9, 1-38.

Vagle, S., and D. M. Farmer (1992), The measurement of bubble-size distributions by acoustical backscatter, J. Atmos. Oceanic Technol., 9, $630-644$.

Wallace, G. T., and R. A. Duce (1978), Open-ocean transport of particulate trace metals by bubbles, Deep Sea Res., 25, 827-835.

Wallace, D. W. R., and C. D. Wirick (1992), Large air-sea gas fluxes associated with breaking waves, Nature, 365, 694-696.

Wang, Q., and E. C. Monahan (1995), The Influence of salinity on the spectra of bubbles formed in breaking wave simulations, in Sea Surface Sound '94, Proceedings of the III International Meeting on Natural Physical Processes Related to Sea Surface Sound, edited by M. J. Buckingham and J. R. Potter, pp. 312-319, World Scientific, Singapore.

Welschmeyer, N. A. (1994), Fluorometric analysis of chlorophyll a in the presence of chlorophyll b and phaeopigments, Limnol. Oceanogr., 39, $1985-1992$ 
Williams, P. J. le B. (1990), The importance of losses during microbial growth: commentary on the physiology, measurement and ecology of the release of dissolved organic material, Mar. Microbiol. Food Webs, 4, $175-206$

Woolf, D. K. (1995), Energy dissipation through wave breaking and the airsea exchange of gases, in Air-Water Gas Transfer, edited by B. Jähne and E. C. Monahan, pp. 185-195, AEON Verlag, Heidelberg.

Woolf, D. K. (1997), Bubbles and their role in gas exchange, in The Sea Surface and Global Change, edited by P. S. Liss and R. A. Duce, pp. 173-205, Cambridge Univ. Press, Cambridge, U.K.

Woolf, D. K., and S. A. Thorpe (1991), Bubbles and the air-sea exchange of gases in near-saturation conditions, J. Mar. Res., 49, 435-466.

Zakharkov, S. P., B. M. Sandler, D. A. Selivanovskiy, A.Yu. Sokolov, Ye. G. Starodubtsev, and P. A. Stunzhas (1991), Gas bubbles and phytoplankton in seawater, Oceanology, 31, 440-441.

Zhou, J., K. Mopper, and U. Passow (1998), The role of surface active carbohydrates in the formation of transparent exopolymer particles by bubble adsorption of seawater, Limnol. Oceanogr., 43, 1860-1871.
Zutic, V., B. Cosovic, E. Marcenko, and N. Bihari (1981), Surfactant production by marine phytoplankton, Mar. Chem., 10, 505-520.

U. Horstmann and V. Kuhnhenn-Dauben, Leibniz-Institut für Meereswissenschaften, Düsternbrooker Weg 20,24105 Kiel, Germany. (vkuhnhenn@ hotmail.com)

U. Knispel and H. Voss, Forschungsanstalt der Bundeswehr für Wasserschall und Geophysik, Klausdorfer Weg 2-24, 24148 Kiel, Germany.

D. A. Purdie, University of Southampton, National Oceanography Centre, European Way, Southampton SO14 3ZH, UK. 